\title{
A cross-cultural exploratory analysis of pandemic growth: The case of COVID-19
}

\author{
Ratan J. S. Dheer ${ }^{1}$, \\ Carolyn P. Egri ${ }^{2}$ and \\ Len J. Treviño ${ }^{3}$
}

${ }^{1}$ Department of Management, College of Business, Eastern Michigan University, Ypsilanti, MI 48197, USA; ${ }^{2}$ Beedie School of Business, Simon Fraser University, Burnaby, Canada; ${ }^{3}$ Department of Management Programs, College of Business, Florida Atlantic University, Boca Raton, FL 33431, USA

Correspondence:

RJS Dheer, Department of Management, College of Business, Eastern Michigan University, Ypsilanti, MI 48197, USA e-mail: rdheer@emich.edu

\begin{abstract}
Although the novel coronavirus that has resulted in more than 3 million deaths and 140 million cases of infection worldwide has wreaked havoc globally, some nations were more successful than others in curbing growth in their number of cases, thereby saving lives. In this research note, we integrate insights from cross-cultural research with inquiry in social psychology and public health literatures to advance a theoretically grounded and culturally derived explanation of cross-national variance in the growth rate of COVID-19. Our multi-level analyses, based on longitudinal time series data from 107 nations, and focused on the first 91 days of this pandemic in different nations, illustrate the direct and interactive effects of culture. Specifically, we find that individualism and uncertainty avoidance have a positive impact, while power distance and masculinity have a negative impact, on the growth rate of COVID19 cases. Three-way interaction analyses between time, government stringency, and culture indicate that early government stringency attenuated pandemic growth, and this attenuation effect was more significant in collectivistic than in individualistic nations, and in high rather than low power distance nations. Our findings provide evidence that can enable policymakers and organizations to develop strategies that not only conform to science but that also consider the cultural orientation of nations.
\end{abstract}

Journal of International Business Studies (2021) 52, |87|-|892.

https://doi.org/ | 0.1057/s4 I 267-02 I-00455-w

Keywords: novel coronavirus; COVID-19; cross-national; government stringency; cultural values

\section{INTRODUCTION}

The COVID-19 pandemic that has resulted in more than 3 million deaths and 140 million cases of infection worldwide to date (JHU, 2020) may become known as the pandemic that irreversibly changed the way we live, work, and interact. It forced governments to initiate mitigation measures, such as closing schools, workplaces, and non-essential businesses, limiting public transportation and gatherings, restricting travel, and issuing stay-at-home orders. Although such measures have been evident globally, their effectiveness in curbing this pandemic's growth varied significantly across nations. For example, while Italy, France, Sweden, and the U.S.A. witnessed an alarming growth in the number of COVID-19 cases over time, New Zealand, Singapore, South Korea, and Taiwan experienced lower case growth. What worked against some and in favor of other nations as they battled this contagion?
All authors contributed equally.

Received: 10 July 2020

Revised: 23 April 2021

Accepted: 26 May 2021

Online publication date: 21 July 2021 
We argue that, while government measures may help to curb growth in the number of cases (Morita, Kato, \& Hayashi, 2020), they do not provide a complete picture. Indeed, the transmission of a communicable disease within a society may also be tied to its culture (Van Bavel et al., 2020), which determines individual behavior and decision-making (Markus \& Kitayama, 1991). Anecdotal evidence points to key culture-based differences in the growth of COVID-19 cases across nations (see Corley, 2020; Van Bavel et al., 2020). In addition, recent research (e.g., Huynh, 2020) highlights culture's effect on society's engagement in social distancing and self-isolation practices. However, our knowledge of culture's role in regulating the growth rate of COVID-19 across nations is incomplete (Wolf, Haddock, Manstead, \& Maio, 2020). Developing this knowledge is necessary to unravel deep-rooted constraints that may hinder nations in their fight against infectious diseases. From a policy standpoint, this can enable governments to devise strategies that not only conform to science but are also informed by how human behavior is shaped by the cultural context, increasing the likelihood of their success in saving lives.

In this research note, we integrate insights from cross-cultural research with inquiry in social psychology and public health literature to advance a theoretically grounded and culturally derived explanation of cross-national variance in the growth rate of COVID-19. Specifically, we theorize that culture will influence a society's belief in the legitimacy of mitigation, thereby directly affecting the growth rate of COVID-19. In addition, culture will also regulate the extent to which a society will conduct its behavior in line with an increase in government stringency to control pandemics, thereby moderating the growth rate of COVID-19 cross-nationally. To test our hypotheses, we employ multi-level hierarchical linear modeling (HLM) growth model procedures (Raudenbush \& Bryk, 2002; Singer \& Willett, 2003) on longitudinal time series COVID-19 case data for 107 nations. Because the early stage of a pandemic is critical to controlling its growth (Chen \& Yu, 2020), we focus on the first three months (91 days) of case data, beginning with the first date that confirmed cases were reported in a nation. In our exploratory analyses, we include daily government stringency as a timevarying predictor of cases, and control for several national-level predictors of pandemics, including population density, median age, and size, economic wealth, healthcare expenditures, and governance strength. We also control for the calendar week that the first case was reported in a nation, and the mean government stringency level over the 91-day period, to model country variation in overall stringency (per Raudenbush \& Bryk, 2002).

Our findings make several notable contributions to international pandemic research. First, our theoretical model responds to calls for a nuanced explanation of cross-national variance in the growth of COVID-19 (Kazak, 2020; Van Bavel et al., 2020). Our research will allow individuals, organizations, and policymakers to effectively mitigate the threats of this pandemic and prepare for similar crises in the future. Second, our investigation of the direct effect of culture and its interactive effects with government stringency is critical to advancing a contextually informed understanding of national response to pandemics. Our analyses demonstrate that cultural differences influenced the growth rate of COVID-19 across nations. Specifically, we show how case growth evolved differently during the first wave of this pandemic in culturally different nations. Third, we highlight the moderating effect of culture by illustrating its impact on the COVID-19 growth rate in nations with comparable government stringency levels at different times. Our findings are vital to underscoring how the impact of a pandemic can vary across nations. These also explain the importance of human behavior in controlling pandemics. Applying our model at the nation-state level will enable governments to save lives and attenuate a pandemic's psychological, social, and economic toll.

\section{THEORY AND HYPOTHESES}

Being a transmissible disease (Jiang, 2020), the spread of COVID-19 will be influenced by individual behavior. Del Valle, Mniszewski, and Hyman (2013) emphasized that a strong, often intentional motivation to adapt behavior is necessary to control a contagion's spread. However, realizing sudden and rapid behavioral shifts is difficult (Berkman, 2018). One factor that may facilitate behavioral changes during a pandemic is the stringency with which governments implement mitigation measures (Anderson, Heesterbeek, Klinkenberg, \& Hollingsworth, 2020). Specifically, given the nature of viral pandemics, where the right course of action is often not obvious and health experts' expertise is questioned (Johnson \& Slovic, 1995), governments are tasked with 
informing the public about optimal behavioral routines (Lee \& Basnyat, 2013). If measures advanced by the government are more stringent, this sends a strong signal that the pandemic poses severe health consequences and life-threatening conditions. Because individuals may be concerned with the economic, social, and psychological implications of such measures (Hsiang et al., 2020), strong signals by the government could lead them to conclude that the benefits of complying with them outweigh their costs.

While stringency is important, it may not solely predict a pandemic's growth trajectory. Cross-cultural and social psychology literatures indicate that mental representations that shape one's evaluation, judgment, and response to external events are based primarily on culturally-derived knowledge (Peterson \& Smith, 2008). Culture offers the lens through which individuals see the world, and it shapes the schema that guides their behavior (Sully De Luque \& Sommer, 2000). Indeed, the effect of formally established rules and guidelines is contingent on a society's cultural frame (Graafland \& Noorderhaven, 2020). As such, culture will determine how individuals interpret and comply with stringent government measures, thus regulating their effectiveness in curbing the growth rate of COVID-19. In addition, culture will determine the extent to which a society acknowledges mitigation as a tactic to control pandemics (Van Bavel et al., 2020). As Smith (2006) noted, sustaining behaviors that enable mitigation has not only epidemiological but also psychological and economic consequences, such as increased stress and job and income losses for millions. This represents a tradeoff that may affect the acknowledgment of mitigation. Assumptions core to behavioral economics indicate that individual behavior is not always rational and consistent with long-term utility maximization (Simon, 1979). During times of uncertainty, stress, and change, individuals rely on culturally derived values, beliefs, and assumptions, enabling them to rationalize their behavior and make socially endorsed decisions.

Following Kirkman, Lowe, and Gibson (2006), we posit that culture will have a direct and moderating effect on cross-national variance in the growth of COVID-19 cases. Specifically, culture will determine the extent to which a society acknowledges mitigation as a justified way to control pandemics. Further, it will influence people's compliance to government stringency, thereby curbing the growth rate of COVID-19 cases over time. Our review of socio-psychological models that acknowledge culture's role (Markus \& Kitayama, 1991; Peterson \& Wood, 2008) suggests that some nations may be more likely to accept mitigation and comply with increased government stringency than others. We leverage Hofstede's (2001) cultural values framework to explain this variance, as it offers a theoretically grounded and validated conceptualization of cultural differences between nations.

\section{Individualism-Collectivism}

Individualism-Collectivism contrasts between nations that prioritize independence over interdependence (Hofstede, 2001). Compared to individualistic nations, collectivistic nations consider that protecting collective interests is more important than the independent self (Kitayama et al., 2018). As such, collectivistic nations will be more likely to acknowledge the usefulness of mitigation. Their sense of shared identity will derive their altruistic behavior (Van Bavel et al., 2020). Further, because collectivistic nations perceive that socially inappropriate behavior may result in community-wide sanctions (Heinrichs et al., 2006), they will be encouraged to accept mitigation to limit the growth of COVID-19. However, because mitigation requires the sacrifice of self-oriented benefits in favor of socially beneficial goals (Wolf et al., 2020), individualistic nations may underestimate its validity, thereby stimulating the growth of COVID-19 cases.

Hypothesis 1a: Individualistic nations will have a higher growth rate of COVID-19 cases over time than collectivistic nations.

An increase in government stringency will also be more tolerated in collectivistic than in individualistic nations. We reason that, because collectivistic nations emphasize duty, obedience, and utilitarian outcomes (Inglehart \& Oyserman, 2004), an increase in government stringency will be less likely to be perceived as a penalty to the self even when it limits individual freedom. Support for this argument comes from Smith, Peterson, \& Schwartz's (2002) finding that rules and regulations are more accepted in collectivistic than in individualistic nations. Chen et al. (2006) also found that collectivistic nations are more likely to comply with strict rules, especially when they are pro-social and purport to benefit society. However, this may not be the case in individualistic nations, where increased government stringency may be perceived 
as an infringement on individual freedom (Hornsey, Harris, \& Fielding, 2018). As such, it may lead to greater anxiety, fear, and resentment. Past research supports this argument by indicating that, while collectivistic nations displayed higher conformity to strict government measures to reduce the spread of H1N1, individualistic nations countered such efforts (Cho \& Lee, 2015).

Hypothesis 1b: Individualism-collectivism will moderate the relationship between government stringency and the growth rate of COVID19 cases, such that government stringency will have a weaker attenuating effect on case growth rate in individualistic than in collectivistic nations.

\section{Power Distance}

Power distance captures the extent to which a society accepts the unequal distribution of power, status, and authority (Hofstede, 1994). Because high power distance nations are more open to following guidelines (Smith et al., 2002), they may be more likely to perceive mitigation as a justified response to countering the threat of infection. However, because low power distance nations are less submissive (Daniels \& Greguras, 2014), they may challenge the legitimacy of mitigation and consider it an infringement on their free will. Indeed, Deschepper et al. (2008) and De Meulenaer, De Pelsmacker, and Dens (2018) found that individuals in high rather than low power distance nations tend to agree with their doctor's recommendations. We posit that high power distance nations will be more likely to acknowledge mitigation, leading to a lower growth rate in COVID-19 cases therein than in low power distance nations.

Hypothesis 2a: High power distance nations will have a lower growth rate of COVID-19 cases over time than low power distance nations.

An increase in government stringency will also stimulate less threat in high compared to low power distance nations. Fischer and Mansell (2009) found that high power distance nations are normatively inclined to obeying rules, while Smith et al. (2002) found that this is not the case with low power distance nations. In addition, Alves, Lovelace, Manz, Matsypura, Toyasaki, and Ke (2006) found that an affirmative leadership style is more tolerated in high than in low power distance nations, where people perceive it as strenuous, restrictive, and debilitating. Indeed, anecdotal evidence suggests that high power distance nations witnessed some success with implementing strict government measures to control COVID-19, such as imposing fines, mandating isolation, and ceasing non-essential activities (Guy \& Griffiths, 2020). However, this was not the case in low power distance nations, where such measures were met with opposition and rage (Pisano, Sadun, \& Zanini, 2020). Accordingly, we posit that an increase in government stringency will be more tolerated in high power distance nations, ultimately leading to a greater attenuating effect on COVID-19 case growth. However, it may face resistance in low power distance nations, leading to a weaker attenuating effect on case growth rate.

Hypothesis 2b: Power distance will moderate the relationship between government stringency and the growth rate of COVID-19 cases, such that government stringency will have a stronger attenuating effect on case growth rate in high than in low power distance nations.

\section{Uncertainty Avoidance}

Uncertainty avoidance reflects the extent to which a society feels threatened by ambiguities. Because high uncertainty avoidance nations perceive such situations as novel but also dangerous, they look for confirmed approaches to reduce uncertainty (Newburry \& Yakova, 2006). Conversely, low uncertainty avoidance nations are more tolerant of ambiguities, which do not increase stress within the population, making it more likely that individuals therein will accept measures with unknown outcomes (Lee, Garbarino, \& Lerman, 2007). Evidence supporting this argument comes from the innovation literature (e.g., Shane, 1995), which suggests that people are more willing to try newer methods and engage in novel experimentation in low than in high uncertainty avoidance nations. Although one can argue that high uncertainty avoidance nations are more likely to acknowledge mitigation to reduce the threat of COVID-19, it may also be that, because mitigation is a novel and uncommon approach to preventing ailments, adopting it, especially during the onset of a pandemic, may amplify anxiety, stress, and frustration. This is also likely because a pandemic's economic and psychological consequences are more apparent during its initial stages than are its health consequences (Ashraf, 2020). Indeed, studies have found that high uncertainty avoidance nations rely on guidelines only when they offer a 
confirmed resolution to issues (Kwok \& Tadesse, 2006). Because mitigation is a preventive and not a definitive means to reduce the threat of contagions (WHO, 2020), it may lead to greater stress and reluctant adoption in high compared to low uncertainty avoidance nations.

Hypothesis 3a: High uncertainty avoidance nations will have a higher growth rate of COVID19 cases over time than low uncertainty avoidance nations.

High uncertainty avoidance nations may also react more negatively to increased government stringency. Hofstede (2001) classified these nations as rigid, where individuals exhibit low tolerance to deviance from prevailing social norms (Taylor, 2000). This is also evident from studies (e.g., Kwok $\&$ Tadesse, 2006) which found that situations that foster greater ambiguity result in lower participation in high uncertainty avoidance nations. Research examining the impact of culture on patient behavior also indicates that those in high uncertainty avoidance nations display less openness to procedures that rely on symptomatic therapy, as it has fewer proven benefits (Borg, 2012). As such, an increase in government stringency may aggravate alienation and fear in high uncertainty avoidance nations. Conversely, in low uncertainty avoidance nations, individuals may be less troubled by increased government stringency, thus facilitating curbing the growth in COVID-19 cases. Smith (2015) found that practices that enable pro-social behaviors are less likely to be perceived as challenging in low uncertainty avoidance nations, as they induce less fear. Finally, individuals in these nations perceive less hostility and more trust in government (Hofstede, 2001; Johnson \& Lenartowicz, 1998), thus increasing the likelihood that they would comply with increased stringency.

Hypothesis 3b: Uncertainty avoidance will moderate the relationship between government stringency and the growth rate of COVID-19 cases, such that government stringency has a weaker attenuating effect on case growth rate in high uncertainty avoidance nations than in low uncertainty avoidance nations.

\section{Masculinity-Femininity}

Masculinity-femininity contrasts between nations that prioritize ego goals versus social goals (Hofstede, 1998). Because feminine nations prioritize values such as service, welfare, and care of others more than assertiveness, achievement, and success, which exemplify masculine nations, individuals in the former may be more motivated to accept mitigation to limit the spread of contagious infections. In support of this reasoning, Borg (2014) found that infection prevention and control are more likely to be successful in feminine than in masculine nations.

Hypothesis 4a: Masculine nations will have a higher growth rate of COVID-19 cases over time than feminine nations.

It can be argued that, because masculine nations display more competitiveness, toughness, and achievement orientation than feminine nations (Hofstede, 2001), they will be more inclined to comply with stringent government measures. However, some evidence suggests that pro-social values that are likely to curb COVID-19 case growth, such as hospitality and service to others, are more established in feminine nations (Wolf et al., 2020). Indeed, research indicates that feminine nations are more likely to lean toward welfare societies (e.g., Johnson \& Lenartowicz, 1998). We posit that an increase in government stringency will be more endorsed in feminine than in masculine nations, facilitating a more significant curb in COVID-19 case growth rate in the former.

Hypothesis 4b: Masculinity-femininity values will moderate the relationship between government stringency and the growth rate of COVID19 cases, such that government stringency has a stronger attenuating effect on case growth rate in feminine than in masculine nations.

\section{METHODOLOGY}

As described in more detail below, we test our hypotheses using data from multiple sources. We employed HLM growth model procedures (Raudenbush \& Bryk, 2002; Singer \& Willett, 2003) to analyze longitudinal time series COVID-19 case data for the 107 nations (9737 observations) that had data for predictor and control variables.

\section{Variables}

\section{COVID-19 cases}

Our outcome variable is the number of new confirmed COVID-19 cases per day per million people (to account for different population sizes). We obtained data from "Our World in Data" (OWID) (https://ourworldindata.org/coronavirus-data; 
downloaded February 2, 2021) that provides daily updates of the number of documented COVID-19 cases reported by the European Centre for Disease Control. ${ }^{1}$ We focused on data for the first three months of COVID-19 cases reported for a nation. Thus, we included a time variable for the day that cases are reported (starting at 0, for the first day a nation reported a COVID-19 confirmed case plus 90 days). We performed exponential smoothing ( $\alpha=$ 0.3 , damping factor $=0.7$ ) for each nation's data to resolve issues such as underreported cases, missing days for reported cases, and overreported data missing in a previous period.

\section{Cultural value dimensions}

We obtained cultural values dimension scores (range of 1 to 100) from Hofstede's website (https://www. hofstede-insights).

\section{Government stringency}

We used the Oxford COVID-19 Government Response Tracker Containment and Health Index ${ }^{2}$ (Hale et al., 2021; downloaded February 2, 2021). This index consists of eight containment and closure policy indicators (e.g., school closures, stay at home requirements, travel restrictions) and five health system policy indicators (e.g., public information campaign, testing, contact tracing, facial coverings), with daily scores ranging from 0 to 100 . Because the impact of government stringency on cases can take approximately two weeks (Allel, Tapia-Muñoz, \& Morris, 2020; Scarabel, Pellis, Bragazzi, \& Wu, 2020), we lagged government stringency scores by 14 days before each day of cases during this time period. ${ }^{3}$

\section{Country control variables}

We controlled for country factors that could affect the growth rate of COVID-19 cases and the effects of government stringency (e.g., Allel et al., 2020). The implementation and impact of government stringency could depend on a nation's population density (log), population median age, and population size (log) (United Nations Population Division, 2019). To control for economic resources to detect and contain the pandemic, we included economic wealth as GDP per capita (purchasing power parity in current international dollars) and healthcare expenditures as a percentage of GDP (World Bank, 2020a). The quality of national governance may also be related to government policies' effectiveness to contain the growth of COVID-19 cases, so we controlled for governance strength by using a composite index of the six governance indicators published by the World Bank (2020b) Worldwide Governance Indicators. ${ }^{4}$ Given that infection rate and government stringency may vary between nations that reported COVID-19 cases during earlier versus later stages of the pandemic, we controlled for the calendar week that the first case was reported $(1=$ December 29,2019 to January 4, 2020; 2 = January 5 to 11,2020 , and so forth). We also included the country mean of government stringency over the 91-day time period to model country variation in overall stringency levels (per Raudenbush \& Bryk, 2002).

\section{Analysis}

We used HLM growth model procedures (Raudenbush \& Bryk, 2002; Singer \& Willett, 2003) to test our hypotheses. HLM is the appropriate analytic approach for multi-level longitudinal data, insofar as it addresses issues of unmeasured heterogeneity across units (i.e., countries) and unbalanced data (e.g., missing daily case report data for countries). In the HLM models, our dependent variable is the number of COVID-19 reported cases. The level-1 variables are time (the day of the time period), time-squared (quadratic term to account for curvilinearity for countries that had shorter initial outbreak periods, per Chien \& Lin, 2020), government stringency (time-varying predictor), and the time $\times$ government stringency interaction term. ${ }^{5}$ In longitudinal growth models with time-varying predictors (Singer \& Willett, 2003), the slope parameter for time is interpreted as the conditional population average rate of change in cases, controlling for the effect of government stringency. The slope parameter for government stringency is the average population effect of stringency on cases, and a significant coefficient for time $\times$ government stringency can indicate either that the rate of change in cases over time differs by stringency level or that the effect of stringency on cases varies over time. Level-1 variables were groupmean centered to reduce potential collinearity among predictors. Thus, the coefficient for growth rate (time) indicates the average rate of growth during the data period, and the intercept reflects the cases per million at the period mid-point (Raudenbush \& Bryk, 2002).

Our level-2 variables (grand-mean centered) are country cultural value dimensions, and controls entered first as baseline main effects. To test Hypotheses 1a, 2a, 3a, and 4a, we added cross-level interactions for the four cultural value dimensions 
on time to estimate moderating effects of cultural values on the growth rate of cases, controlling for government stringency level. To test Hypotheses $1 \mathrm{~b}, 2 \mathrm{~b}, 3 \mathrm{~b}$, and $4 \mathrm{~b}$, we added the cultural value dimensions cross-level interactions on the time $x$ government stringency term to estimate the moderating effects of cultural value on the relationship between government stringency and growth rate of cases over time. ${ }^{6}$ We provide illustrative figures at high and low levels ( $\pm 1 \mathrm{SD}$ ) of the cultural values dimensions to interpret significant cross-level moderating effects of cultural value dimensions on case growth rate. To interpret the significant three-way interactions (cultural values $\times$ time $\times$ government stringency), we conducted post hoc analyses to assess whether the effect of stringency varies over time (per Raudenbush \& Bryk, 2002; Singer \& Willett, 2003). For these analyses, we examined the trajectories of case growth at five time-points (days $0,15,30,45$, and 60; recentered time for days 15-60) for high and low cultural values and government stringency levels. For each selected case day, we constructed sets of dummy variables for government stringency (lagged by 14 days previous). Given the increasing stringency throughout the time period (average stringency level ranged from 5.9 for day 0 to 61.9 for day 60), we constructed stringency categories so that there was a sufficient number of countries in each group.

\section{Results}

In Table 1, we present results for the final HLM model. Time (growth rate of cases per million) is positive $\left(\gamma_{10}=0.618, p=0.005\right)$ and there is a significant curvilinear effect (time sq.: $\gamma_{20}=0.005, \mathrm{p}$ $=0.022$ ). Cultural value dimensions have significant cross-level moderating effects on case growth rate (time) such that individualism and uncertainty avoidance have positive (respectively, $\gamma_{11}=0.014$, $\left.p=0.005 ; \gamma_{13}=0.008, p=0.037\right)$, whereas power distance and masculinity have negative effects (respectively, $\gamma_{12}=-0.010, p=0.039 ; \gamma_{14}=$ $-0.008, p=0.082$ ). As illustrated in Figure $1 \mathrm{a}-\mathrm{d}$, the growth rate of cases is positive and curvilinear for individualistic, low power distance, low uncertainty avoidance, and feminine nations. In

Table 1. Influences on COVID-19 cases per million population ${ }^{\mathrm{a}}$

\begin{tabular}{|c|c|c|c|c|c|c|c|}
\hline & & & Coeff. & SE & $\mathrm{t}$ value & $p$ & df \\
\hline & Intercept & $\gamma_{00}$ & 10.808 & 1.617 & 6.680 & 0.000 & 94 \\
\hline & Individualism & $\gamma_{01}$ & 0.199 & 0.079 & 2.518 & 0.013 & 94 \\
\hline & Power distance & $\gamma_{02}$ & -0.056 & 0.078 & -0.712 & 0.478 & 94 \\
\hline & Uncertainty avoidance & $\gamma_{03}$ & 0.117 & 0.060 & 1.941 & 0.055 & 94 \\
\hline & Masculinity & $\gamma_{04}$ & -0.128 & 0.067 & -1.893 & 0.061 & 94 \\
\hline & Population median age & $\gamma_{05}$ & 0.048 & 0.154 & 0.310 & 0.757 & 94 \\
\hline & Population density (log) & $\gamma_{06}$ & -0.467 & 0.576 & -0.810 & 0.420 & 94 \\
\hline & Population size (log) & $\gamma_{07}$ & 1.918 & 1.411 & 1.359 & 0.177 & 94 \\
\hline & Governance & $\gamma_{08}$ & 0.583 & 1.449 & 0.402 & 0.688 & 94 \\
\hline & Economic wealth & $\gamma_{09}$ & 2.177 & 1.354 & 1.608 & 0.111 & 94 \\
\hline & Health expenditures & $\gamma_{010}$ & -0.018 & 0.347 & -0.051 & 0.960 & 94 \\
\hline & Calendar week & $\gamma_{011}$ & 0.373 & 0.473 & 0.788 & 0.432 & 94 \\
\hline & Government stringency (mean) & $\gamma_{012}$ & 0.180 & 0.088 & 2.040 & 0.044 & 94 \\
\hline & Time & $\gamma_{10}$ & 0.618 & 0.215 & 2.878 & 0.005 & 102 \\
\hline $\mathrm{H} 1 \mathrm{a}$ & $\times$ Individualism & $\gamma_{11}$ & 0.014 & 0.005 & 2.631 & 0.010 & 102 \\
\hline $\mathrm{H} 2 \mathrm{a}$ & $\times$ Power distance & $\gamma_{12}$ & -0.010 & 0.005 & -1.933 & 0.056 & 102 \\
\hline $\mathrm{H} 3 \mathrm{a}$ & $\times$ Uncertainty avoidance & $\gamma_{13}$ & 0.008 & 0.003 & 2.141 & 0.035 & 102 \\
\hline \multirow[t]{4}{*}{$\mathrm{H} 4 \mathrm{a}$} & $\times$ Masculinity & $\gamma_{14}$ & -0.008 & 0.004 & -1.754 & 0.082 & 102 \\
\hline & Time sq. & $\gamma_{20}$ & 0.005 & 0.002 & 2.318 & 0.022 & 106 \\
\hline & Government stringency & $\gamma_{30}$ & 0.093 & 0.094 & 0.986 & 0.326 & 106 \\
\hline & Time $\times$ stringency & $\gamma_{40}$ & -0.014 & 0.006 & -2.747 & 0.007 & 102 \\
\hline $\mathrm{H} 1 \mathrm{~b}$ & × Individualism & $\gamma_{41}$ & -0.0004 & 0.0001 & -2.484 & 0.015 & 102 \\
\hline $\mathrm{H} 2 \mathrm{~b}$ & $\times$ Power distance & $\gamma_{42}$ & 0.0004 & 0.0001 & 2.332 & 0.022 & 102 \\
\hline $\mathrm{H} 3 \mathrm{~b}$ & $\times$ Uncertainty avoidance & $\gamma_{43}$ & -0.0001 & 0.0001 & -0.921 & 0.359 & 102 \\
\hline $\mathrm{H} 4 \mathrm{~b}$ & $\times$ Masculinity & $\gamma_{44}$ & 0.0002 & 0.0002 & 1.222 & 0.225 & 102 \\
\hline
\end{tabular}

H1a Hypothesis $1 \mathrm{a}$, et seq.

${ }^{a} \mathrm{n}=107$ countries, 9737 observations 
(a) Individualism/collectivism and COVID-19 case growth rate

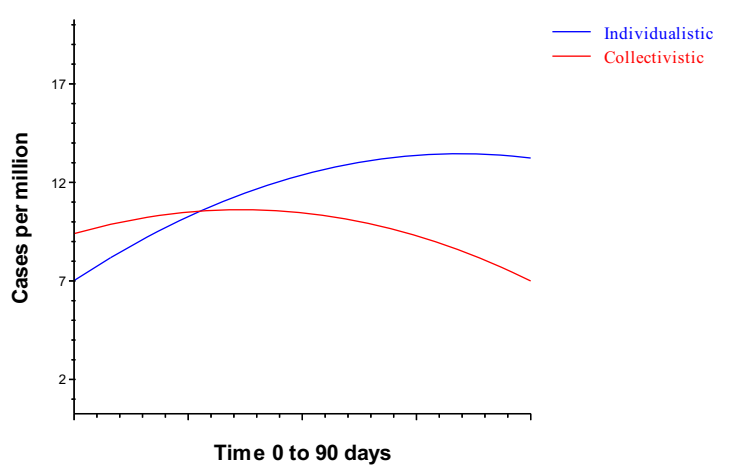

(b) Power distance and COVID-19 case growth rate

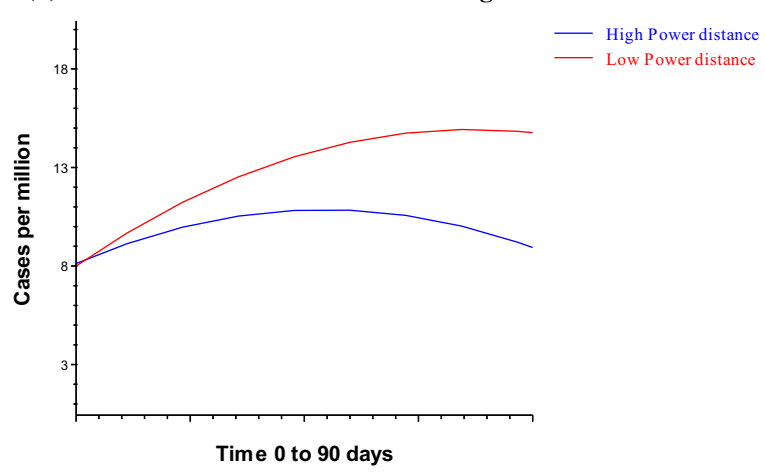

(c) Uncertainty avoidance and COVID-19 case growth rate

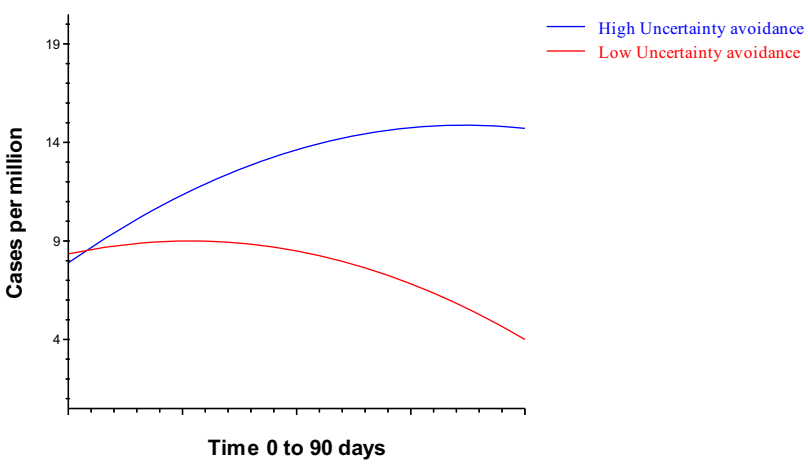

(d) Masculinity/Femininity and COVID-19 case growth rate

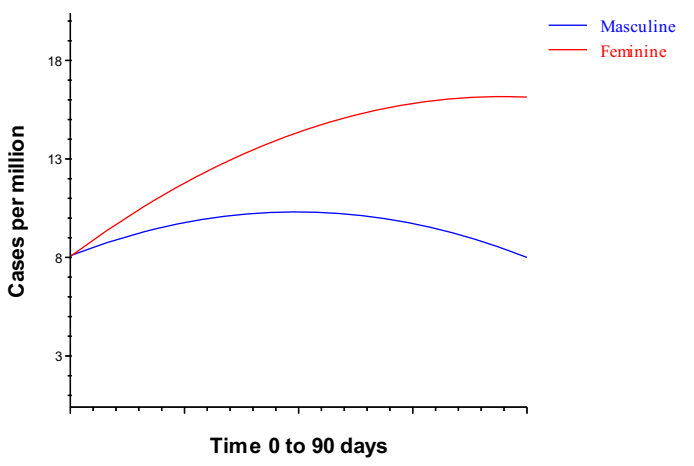

Figure 1 a Individualism-collectivism and COVID-19 case growth rate. b Power distance and COVID-19 case growth rate. c Uncertainty avoidance and COVID-19 case growth rate. d Masculinity-femininity and COVID-19 case growth rate.

contrast, we found an inverted U-shaped curvilinear relationship for collectivistic, high power distance, and masculine nations and a decreasing curvilinear relationship in low uncertainty avoidance nations. Hence, Hypotheses $1 \mathrm{a}, 2 \mathrm{a}$, and $3 \mathrm{a}$ are supported, and $4 \mathrm{a}$ is not supported.

As shown in Table 1, even though the population average effect of lagged government stringency (level-1 time-varying predictor) is not significant $\left(\gamma_{30}=0.093, p=0.326\right)$, the aggregate mean government stringency is positively related to cases per million $\left(\gamma_{012}=0.180, p=0.044\right)$. The effect of time $\times$ government stringency interaction on cases per million is significant $\left(\gamma_{40}=-0.014, p=0.007\right)$. Uncertainty avoidance and masculinity do not moderate the effect of time $\times$ government stringency on cases ( $p=0.359, p=0.225$ respectively), hence Hypotheses $3 \mathrm{~b}$ and $4 \mathrm{~b}$ are not supported. However, individualism and power distance significantly moderate this relationship (respectively, $\gamma_{41}$ $\left.=-0.0004, p=0.015 ; \gamma_{42}=0.0004, p=0.022\right)$, and we present Figures $2 \mathrm{a}-\mathrm{e}$ and $3 \mathrm{a}-\mathrm{e}$ to illustrate these interactions.

\section{Individualism-collectivism, government stringency, and case growth rate}

As shown in Figure 2a (time 0-90 days), individualistic nations have lower initial cases per million than collectivistic nations for each stringency category. For both individualistic and collectivistic nations, the effect of higher stringency measures implemented 14 days prior to cases is reflected by the lower initial cases per million for nations that have stringency of 20 or more, compared to those with 10-19 stringency, with the highest initial cases per million for nations with stringency less than 10. The trajectory of case growth in individualistic nations is curvilinear and positive, with inflection points being at day 78 for nations with stringency less than 10 and 64 for nations with higher stringency (10-19, and 20+). The case growth trajectory in collectivistic nations has an inverted U-shape with inflection points for decreasing cases being later for nations with a low stringency level (day 36; <10 stringency level) than for nations with higher stringency (day 21). Two weeks into the pandemic for each nation (Figure 2b; time 
(a) Time 0 to 90 days

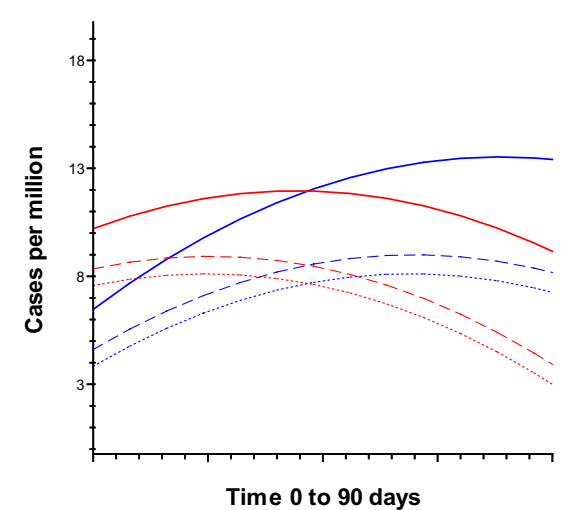

(c) Time 30 to 90 days

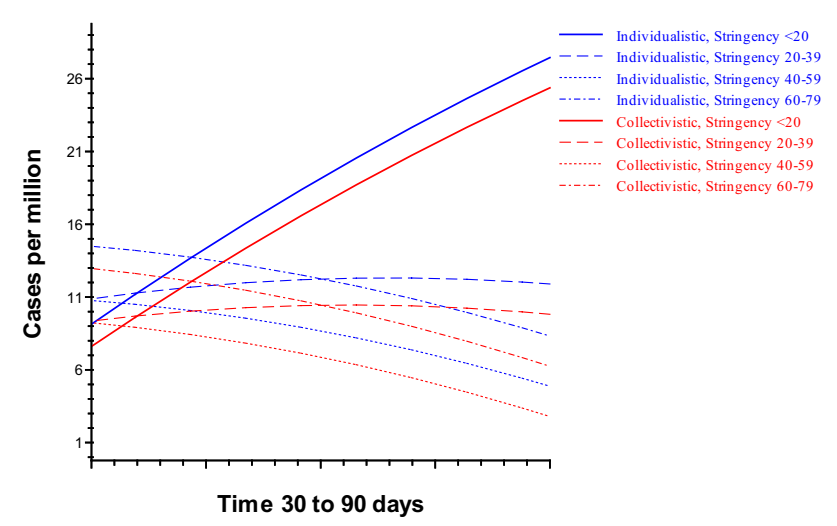

(e) Time 60 to 90 days

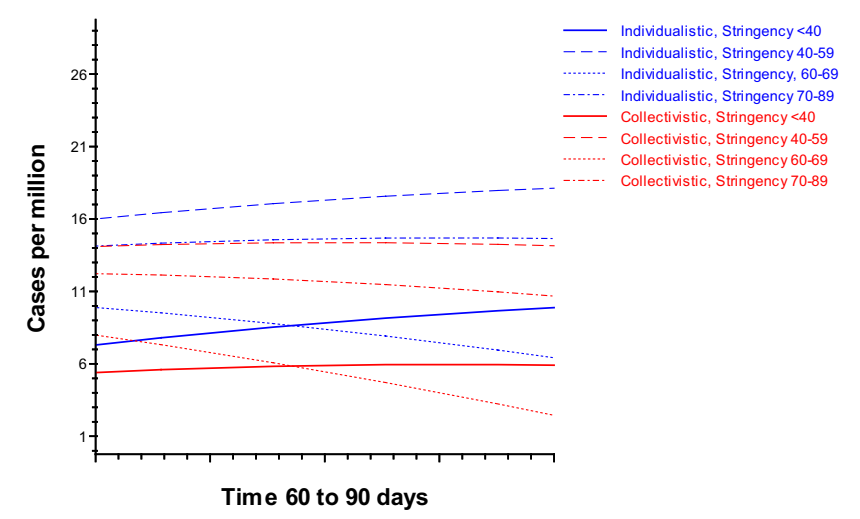

(b) Time 15 to 90 days

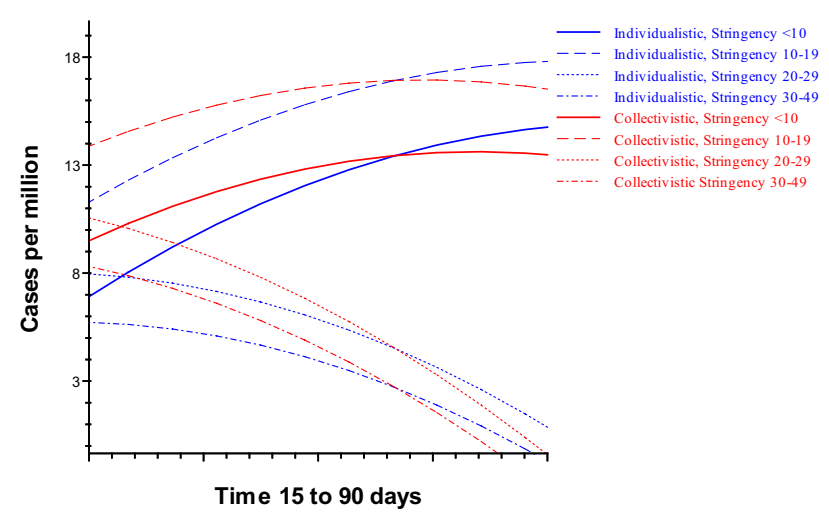

(d) Time 45 to 90 days

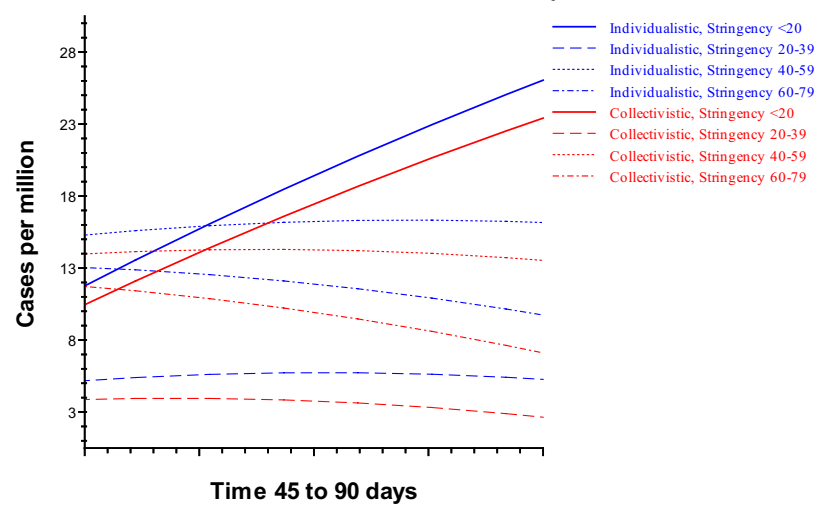

Figure 2 Individualism-collectivism, government stringency, and COVID-19 case growth rate. a Time 0-90 days. b Time 15-90 days. c Time 30-90 days. d Time 45-90 days. e Time 60-90 days.

15-90 days), nations with lower stringency $(<10$, 10-19) had positive curvilinear case growth rates, with these being steeper for individualistic than collectivistic nations. Nations with higher stringency (20 or more) had negative curvilinear case growth rates, with these being steeper for 
(a) Time 0 to 90 days

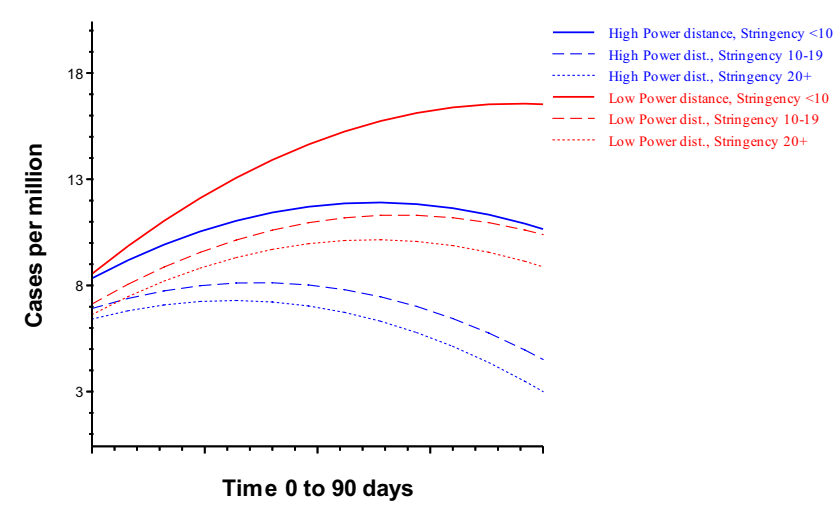

(c) Time 30 to 90 days

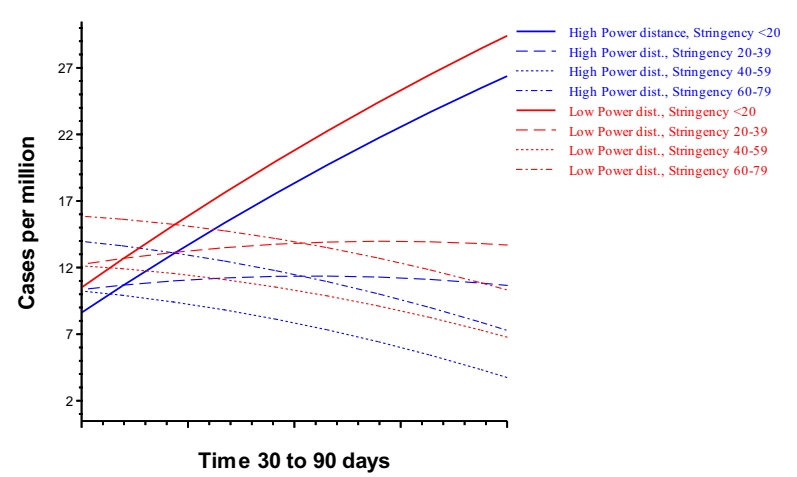

(e) Time 60 to 90 days

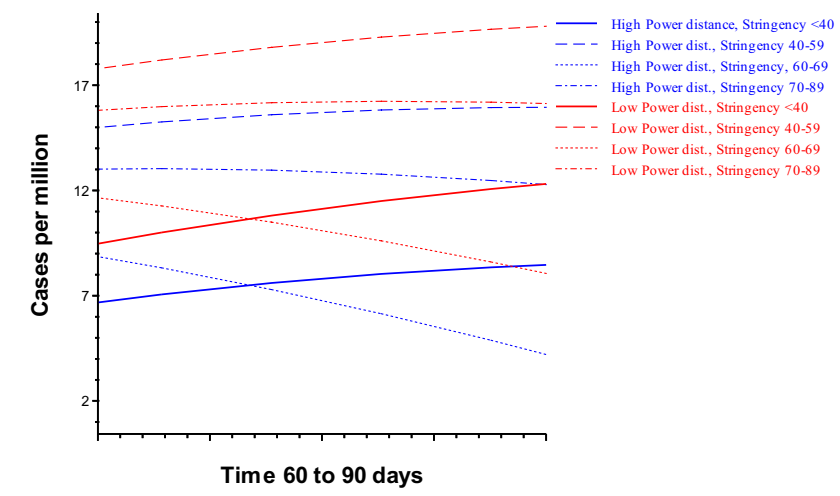

(b) Time 15 to 90 days

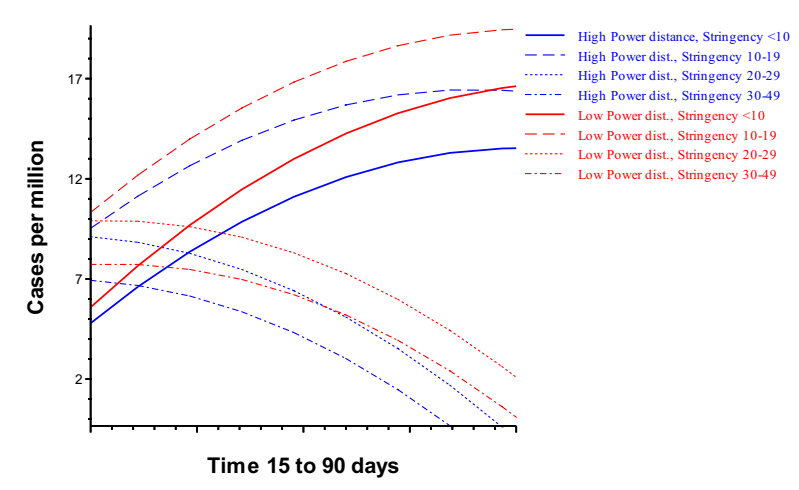

(d) Time 45 to 90 days

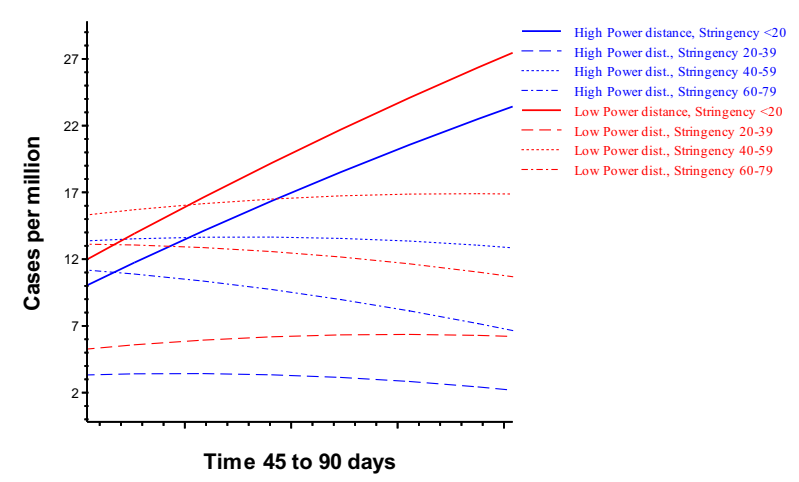

Figure 3 Power distance, government stringency, and COVID-19 case growth rate. a Time 0-90 days. b Time 15-90 days. c Time 30-90 days. d Time 45-90 days. e Time 60-90 days.

collectivistic nations. At later times during this three-month period (Figure 2c-e), the effect of stringency on case growth was similar for individualistic and collectivistic nations; however, the number of cases per million was higher for individualistic than for collectivistic nations in each stringency category. Nations that had a low stringency $(<20)$ two weeks prior to day 30 (Figure 2c) and day 45 (Figure $2 \mathrm{~d}$ ) had a positive case growth trajectory. Nations with stronger stringency (40 or more) prior to day 30 (Figure 2c) had a negative case growth trajectory, while this was limited to 
nations with higher stringency (40 or more) prior to day 45 (Figure 2d) and then to nations with 60-69 stringency levels two weeks later (Figure 3e).

In sum, our analyses support Hypothesis $1 \mathrm{~b}$ in that government stringency has a more substantial attenuating effect on case growth in collectivistic than individualistic nations during the early period of the COVID-19 pandemic in a nation. Subsequent to the first month, the case growth trajectory is similar for individualistic and collectivistic nations with progressively higher levels of government stringency needed to curb case growth.

\section{Power distance, government stringency, and case growth rate}

As shown in Figure 3a (time 0-90 days), both high and low power distance nations in each stringency category have similar initial cases per million, although the number of cases is higher for nations with a low stringency $(<10)$. For high power distance nations, the case growth trajectory is an inverted U-shape with inflection points earlier (day 29) for nations with higher stringency (day 36 for 10-19 stringency; day 29 for $\geq 20$ stringency) than for nations with a low stringency (day 57; $<10$ stringency). For nations with a low stringency $(<10)$, there is a positive curvilinear case growth trajectory for low power distance nations, whereas case growth has an inverted U-shape for high power distance nations (inflection point at day 57). For nations with higher stringency levels $(10-19 ; \geq 20)$, case growth has an inverted U-shape with the inflection points being earlier for high power distance nations (day 36 for 10-19 level; day 29 for $\geq 20$ level) than for low power distance nations (day 57 for 10-9 level; day 57 for $\geq 20$ level). Two weeks into the pandemic in each nation (Figure 3b; time 15-90 days), the cases per million were lower in high power distance nations than in low power distance nations in each stringency category. There was a positive curvilinear case growth trajectory for nations with low stringency $(<10,10-19)$, although the dampening effect of stringency on case growth was more significant in high power distance nations than in low power distance nations. For nations that had implemented stronger stringency (20-29, 30-49 levels), there was negative curvilinear case growth, with this being more pronounced in high power distance nations. Later during this three-month period (Figure 3c-e), the effect of stringency on case growth was similar for high and low power distance nations. Nations that still had a low stringency $(<20)$ prior to days 30 and 40
(Figure 3c, d) had a positive case growth trajectory, as did nations that had stringency below 40 prior to day 60 (Figure 3e).

In sum, our analyses support Hypothesis $2 \mathrm{~b}$ in that government stringency has a more substantial attenuating effect on case growth in high than in low power distance nations, particularly during the early period of the COVID-19 pandemic in a nation.v

\section{Robustness Tests}

We conducted additional analyses to test the robustness of our findings. Analyses using 7-day moving average case data yielded very similar results. Analyses using nonsmoothed case data with missing daily case reports and analyses beginning on the day that there was a total of at least five confirmed cases differed slightly in that masculinity did not significantly moderate case growth rate (respectively, $p=0.214, p=0.264$ ). While some studies have used COVID-19 test data for robustness tests of underreporting of cases (e.g., Gelfand et al., 2021), this robustness test is not possible given significant missing test data for our sample countries. Complete daily test data for the first 91-day time period is only available for 18 countries. Less than 60 days of test data were available for 29 countries. No daily test data are available for 24 countries (4 of which only report weekly test data).

\section{Alternative cultural dimensions}

We conducted analyses using alternative cultural dimensions from Schwartz (2006; 73 nations) ${ }^{7}$; the GLOBE project (House, Hanges, Javidan, Dorfman, \& Gupta, 2004; 53 nations; cultural practices); and the World Values Survey (Inglehart et al., 2014; 76 nations). Consistent with Hypotheses 1a, 1b (individualism-collectivism), case growth rates were positive and curvilinear for individualistic nations, i.e., SVS autonomy, GLOBE low ingroup collectivism, WVS self-expression (respectively, $\gamma=0.292$, $p=0.002 ; \gamma=-0.263, p=0.017 ; \gamma=-0.230, p=$ 0.001 ). In collectivistic nations (SVS embeddedness, GLOBE high ingroup collectivism, WVS survival), case growth rates had an inverted U-shaped curvilinear relationship over time, and government stringency had a stronger attenuating effect on case growth rates (respectively, $\gamma=-.010, p=0.005$; $\gamma=0.009, p=0.025 ; \gamma=0.006, p=0.014)$. However, GLOBE institutional collectivism did not have significant moderating effects $(p=-.374, p=0.262)$. 
Consistent with Hypotheses 2a, 2b (power distance), nations with high SVS hierarchy and high GLOBE power distance had an inverted U-shaped curvilinear growth rate over time, whereas nations with SVS egalitarian and low GLOBE power distance had an increasing curvilinear case growth rate (respectively, $\gamma=-0.392, p=0.013 ; \gamma=-0.506, p=$ 0.046). In both SVS hierarchy and high GLOBE power distance nations, government stringency had a stronger attenuating effect on case growth rate (respectively, $\gamma=0.009, p=0.034 ; \gamma=0.014, p=$ 0.013).

Consistent with Hypotheses 3a, b (uncertainty avoidance), there was a decreasing curvilinear case growth rate in low GLOBE uncertainty avoidance nations and an increasing curvilinear case growth rate in high uncertainty avoidance nations $(\gamma=$ $0.341, p=0.047)$. Government stringency had a more substantial attenuating effect on the case growth rate in low uncertainty nations $(\gamma=$ $-0.012, p=0.072$ ).

Consistent with Hypothesis 4a (masculinityfemininity), the case growth rate was increasing and curvilinear in low GLOBE humane orientation nations and inverted U-shape in high humane orientation nations $(\gamma=-0.300, p=0.070)$. However, GLOBE humane orientation did not moderate the effect of government stringency on case growth rate $(p=0.665)$. Further, other related masculinity-femininity dimensions (SVS masteryharmony, GLOBE assertiveness and gender egalitarianism) did not have significant moderating effects (range $p=0.266$ to $p=0.780$ ).

Although not hypothesized, we examined the effect of Hofstede's long-term orientation (93 countries) and GLOBE future orientation practices. While the case growth rate was not significantly moderated by long-term orientation ( $p=0.627)$, it was increasing and curvilinear in high future orientation nations while decreasing and curvilinear in low future orientation nations $(\gamma=0.438, p=$ 0.092). Further, government stringency had a stronger attenuating effect on case growth rate in nations with shorter time orientations than those with longer time orientations (long-term orientation: $\gamma=-0.0002, p=0.071$; future orientation: $\gamma=$ $-0.016, p=0.076)$. We also examined the moderating effects of Uz's (2015) combined CLT (cultural looseness-tightness) index of within-country variation in cultural values, norms, and behaviors (60 countries). CLT moderated case growth rate $(\gamma=$ $0.024, p<0.001$ ) such that it is positive and curvilinear in culturally loose nations, whereas it has an inverted U-shaped relationship in culturally tight nations. Further, government stringency had a stronger attenuating effect on case growth rate in tight than in loose nations $(\gamma=0.006, p<0.001)$. Analyses using Gelfand et al.'s (2021) cultural tightness-looseness measure (52 countries) did not show significant moderating effects on either case growth rate $(\gamma=-0.317, p=0.212)$ or the effect of government stringency over time $(\gamma=$ $0.008, p=0.343)$.

\section{DISCUSSION}

We illustrate the direct and interactive effects of culture with government stringency on cross-national variance in the growth rate of COVID-19 cases over time. Because slowing the exponential increase in cases during the early phase of a pandemic is critical to providing public service agencies time to prepare and respond without overwhelming healthcare systems, ultimately saving lives (Anderson et al., 2020), we focused on the first three months (91 days) of COVID-19 case data for 107 nations. We leveraged a culture-centric behaviorist perspective, and used Hofstede's cultural value dimensions to highlight why some nations were better able to control the initial surge in COVID-19 cases than others. Our exploratory multi-level analyses controlled for national differences in population, economic, healthcare, and governance indicators, weekly case reports, and mean government stringency level, and explained variance in case growth rate between nations with different cultural conditions. We also highlighted the effect of government stringency and demonstrated how it was contingent on a nation's cultural context.

Regarding our analysis of culture's direct effect, we found that collectivistic nations experienced lower case growth over time than individualistic nations. This finding suggests that a cultural tendency to look beyond the self and consider others' welfare, even if it means sacrificing individual freedoms, will encourage individuals to acknowledge mitigation, allowing societies to curb a pandemic's growth (evident from the inverted U-shape plot; Figure 1a). This finding is consistent with Fincher, Thornhill, Murray, and Schaller (2008) thesis that behaviors that define collectivism are more likely to attenuate the rate of pathogen transmission, while those that define individualism may intensify it. It is also consistent with Biddlestone, Green, and Douglas (2020), who found that 
emphasis on social norms and cooperation is likely to enable collectivistic societies to implement adaptive behavioral responses, facilitating defense against pathogen transmission. Conversely, a lack of emphasis on these values is likely to make individualistic societies more prone to a surge in cases. This cultural difference was evident in comparing collectivistic nations, such as South Korea and Singapore, that emphasized civic awareness and collective efforts (Fisher \& Sang-Hun, 2020) to individualistic nations, such as the U.S.A. and Italy, that were skeptical of mitigation (Pisano et al., 2020). It is also supported by our analysis of the alternate cultural dimensions of self-expression (Inglehart \& Oyserman, 2004), autonomy (Schwartz, 2006), and ingroup collectivism (House et al., 2004), revealing that societies that value individual freedom and choice witnessed a more positive growth rate of COVID-19 cases than those that value cooperation and collective welfare. Interestingly, our plot of case growth (Figure 1a) illustrated that, even though collectivistic nations started with more cases than individualistic nations, consistent with Fincher et al.'s (2008) finding of a positive association between collectivism and pathogen prevalence, they are more likely to engage in behavioral defense mechanisms, thus curbing infection transmission over time.

We found power distance to negatively affect the number of COVID-19 cases, such that, over time, case growth was lower in high than in low power distance nations. Cross-cultural research suggests that high power distance societies are more likely to accept differences in knowledge and intellectual capabilities (Hofstede, 1983), display obedience, and be led by others (Ji, Zhou, Li, \& Yan, 2015). Conversely, subjecting oneself to others is deemed less appropriate in low power distance nations (Hofstede, 2001), where people value free will and are more likely to question experts (De Meulenaer et al., 2018). Our analysis extends these theoretical perspectives into the public health domain by suggesting that societies that are culturally less attuned to following directions and displaying obedience may also be less inclined toward social mitigation, thus limiting their ability to curb pathogen transmission. This was evident in Germany, where people protested against social mitigation (Nienaber \& Chambers, 2020). However, people in high power distance nations, such as Japan and Taiwan, practiced social distancing, selfisolation, and wearing masks despite the absence of absolute lockdowns. Our analysis of the alternate cultural dimensions of hierarchy egalitarianism and GLOBE power distance also indicates that nations with a cultural mindset inclined toward conformity were better able to control COVID-19 case growth than those that leaned toward encouraging selfexperiences and interests. It is likely that the need to justify guidelines, evident in low power distance nations (Sagiv, Schwartz, \& Arieli, 2011), made them more susceptible to infection transmission and countered the positive effects of social mitigation.

Case growth was also more positive and curvilinear in high while decreasing curvilinear in low uncertainty avoidance nations. While thoughtprovoking, this finding supported our contention that acknowledging mitigation may raise stress in high uncertainty avoidance nations that may find the 'cure to be worse than the disease.' This outcome is also likely as, during the initial stage of COVID-19, confusion and controversy about the health benefits of mitigation prevailed (Tufekci, 2020), although its economic and psychological repercussions were evident (Brooks et al., 2020). These factors may have heightened fear and skepticism among high uncertainty avoidance nations, as they are more risk-averse and less likely to engage in experimentation than low uncertainty avoidance nations (Ndubisi, Malhotra, Ulas, \& Ndubisi, 2012). This finding is consistent with Borg (2014), who noted that high uncertainty avoidance nations are more averse to changes, making them less likely to adopt mitigation than low uncertainty avoidance nations. Because incorrect and inconsistent information may increase ambiguity (Wenzel, 2019), we posit that disseminating factual information about the pandemic may be one way to attenuate its growth in high uncertainty avoidance nations. Interestingly, Kim, Ahn, Atkinson, and Kahlor (2020) found that exposure to misinformation was more strongly associated with information avoidance and heuristic thinking in high than in low uncertainty avoidance nations. Our analysis of the alternate GLOBE uncertainty avoidance dimension supported our finding, insofar as it revealed a decreasing curvilinear case growth rate in low and an increasing curvilinear case growth rate in high uncertainty avoidance nations.

Concerning masculinity-femininity, we found inconsistent results using various measures of this cultural dimension. Specifically, our findings based on Hofstede's masculinity-femininity index differed from our theoretical arguments, in that the case growth trajectory was positive and curvilinear 
in feminine while inverted U-shaped curvilinear in masculine nations, indicating that the COVID-19 cases grew more in the former than in the latter (Figure 1d). However, our theoretical arguments were supported by the positive and curvilinear case growth trajectory in low GLOBE humane orientation nations, and the inverted U-shaped curvilinear case growth in high GLOBE humane orientation nations. One can interpret that a society's focus on achievement and performance (Hofstede, 1994) may encourage people to practice social mitigation, hoping they will emerge successful in their fight against a pandemic. However, curbing pandemic growth may also be likely when a society balances this focus with an emphasis on altruistic behaviors and responsibility for the well-being of others (House et al., 2004).

While the explanation of culture's direct effect contributes to cross-national pandemic research, it may be insufficient in isolation. As a novel extension to culture's role, we underscore its interactive effects with government stringency. We found significant three-way interaction for two of Hofstede's cultural dimensions. As expected, we found that higher government stringency attenuated case growth rate and that the individualism-collectivism dimension moderated this relationship. Our depiction of case growth trajectories at different time points and across different stringency categories (Figure 2a-e) illustrates the significant three-way interaction. These findings suggest that early government response is critical in stemming pandemic growth, as nations that implemented more stringent measures early on witnessed lower initial cases per million (Figure 2a) and were also able to curb case growth over time. Further, the attenuation effect of government stringency on case growth rate varied between collectivistic and individualistic nations, such that, for similar stringency levels, collectivistic nations witnessed more substantial attenuation than individualistic nations. One can infer that the cultural emphasis on collective welfare and utilitarian outcomes is more likely to enable individuals to endure government stringency and perceive that the social benefits of compliance outweigh costs to the self. While the consequences of collectivism in stimulating social benefits are outlined (e.g., Wagner III, 1995), we found that collectivism also enables stricter government measures to attenuate infection transmission. Our results support extant research that geographic mobility decreased more in response to strict lockdowns in collectivistic than in individualistic nations (Frey, Chen, \& Presidente, 2020), and that, while collectivistic nations complied with severe government measures, several individualistic nations criticized them as being too interventionist (Lazarus et al., 2020). It also supports Su et al. (2020) finding that individuals in Italy felt a greater loss of leisure and freedom from strict government measures than those in China, who also leveraged their collective identity to engage in adaptive behaviors. The boundedness of government stringency to cultural collectivism is also supported by our analysis of the alternate cultural dimensions of embeddedness (Schwartz, 2006), in-group collectivism (House et al., 2004), survival self-expression (Inglehart \& Oyserman, 2004), and Uz's (2015) cultural tightnesslooseness index. We did not find support for the interaction effect of GLOBE's institutional collectivism or Gelfand et al.'s (2021) tightness-looseness measure.

The effect of government stringency on case growth over time also varied between high and low power distance nations. Our illustration of this three-way interaction (Figure 3a-e) indicates that more robust and early government stringency resulted in lower initial cases and more substantial attenuation of case growth over time. In addition, for similar stringency levels, high power distance nations witnessed a more significant attenuation effect than low power distance nations. This finding supports our theory that social values that instill obedience, direction, and obligation to rules and authority may enable governments to implement strict mitigation policies and garner compliance, thus curbing infection transmission. It also supports Tyler, Lind, and Huo (2000) who argued that, in evaluating authoritative policies, individuals in high power distance nations value the favorability of the outcome of these policies, while those in low power distance nations value their quality. In line with this reasoning, our study suggests that government stringency, despite incurring adverse psychological effects (Brooks et al., 2020), may be perceived more favorably in high power distance nations, thereby enabling compliance and a more substantial attenuation in COVID19 case growth therein, compared to in low power distance nations. One can infer that governments, despite stringency measures, may be less likely to alleviate a health crisis if the cultural context does not support compliance. Therefore, evaluating the cultural environment is critical to ensuring the effectiveness and persuasiveness of government control measures. Our research is likely to explain why nations such as Taiwan and Singapore were 
able to implement strict measures and ensure compliance (Guy \& Griffiths, 2020), while others, such as the U.K., Italy, and Switzerland, witnessed dwindling public faith and even protests (Nivette et al., 2021). Results for Schwartz's (2006) hierarchy and GLOBE's power distance dimensions further support our theory that governments' authority in high power distance nations may facilitate curbing pandemic growth by ensuring compliance to social coordination rules.

\section{Implications for Policymakers}

A crucial question for policymakers is how can public policies facilitate a community-wide response to pandemics when culture is slow to change (Beugelsdijk, Maseland, \& Hoorn, 2015) and behavioral changes that are inconsistent with cultural values are necessary to control pandemics (Bish \& Michie, 2010). One way to realize this objective is to ensure that the implementation of policies is mindful of a society's dominant culture. Specifically, policymakers should recognize how cultural values influence their society's thinking, decision-making, and behavior, and devise strategies that are aligned with their nation's cultural context. For instance, in individualistic nations, where individuals perceive more stress and hardships from adopting mitigation and complying with strict government measures (Biddlestone et al., 2020), policymakers should support individual adversity. Providing incentives, such as unemployment benefits, healthcare, and subsidies for basic necessities in this scenario can mitigate negative psychological experiences and signal that practicing mitigation to support societal welfare is not in vain. In addition, emphasizing a collective response to individual health and financial standing can also promote public participation (Biddlestone et al., 2020). Our findings suggest that it is crucial for governments in individualistic nations to employ concrete, concerted, and coordinated efforts to support behavioral changes early during a pandemic, realizing the lower likelihood of compliance with public health measures for extended durations.

Likewise, policymakers in low power distance nations should understand that authoritative leadership and reliance on rules might be less likely to foster compliance and support for behavioral interventions. Thus, a consultative form of leadership, where individuals feel empowered to practice prosocial behavior, may be more appropriate (Westjohn, Magnusson, Peng, \& Jung, 2019). In this context, policies should focus on providing the right tools for individuals to make decisions.
Providing factual and scientific information regarding the crisis, leveraging knowledge from past pandemics, fostering support from the media, local governing bodies, public service agencies, and nongoverning bodies may enable policymakers to encourage public compliance in low power distance nations. Further, engaging with the public, debating the positive and negative effects of stringency, and providing a supportive infrastructure to counter adverse effects may also facilitate mitigation. While a pandemic can stimulate political bickering (e.g., Lavazza \& Farina, 2020), policymakers should set aside partisanship and self-interested subjectivity in favor of science-based protocols.

Policymakers in high uncertainty avoidance nations should realize that mitigation practices are uncommon and may heighten stress and anxiety, especially during the early phase of a pandemic. Because social structures and psychological tendencies are rigid in these societies (Smith, 2015), individuals may be less likely to alter their behavior. In addition, stress may result from the delay in realizing explicit benefits from preventive strategies, and reducing stress will be as important as the health benefits that preventive measures promise. Communicating transparently with the public can enable policymakers in such contexts to assuage fear while informing citizens of the relevance of timely social intervention. While disseminating misinformation can lead to information avoidance and heuristic decision-making in high uncertainty avoidance nations (Kim et al., 2020), sharing factual and rational information can establish trust (Zhou, Zafarani, Shu, \& Liu, 2019). Thus, policymakers should be transparent and provide factual information to encourage a positive social response to mitigation.

Finally, while feminine values are associated with infection prevention and control of behavior (Borg, 2014), we found that COVID-19 case growth was curbed more in masculine than in feminine nations. Notably, our subsidiary analyses showed that the case growth rate in nations with a high humane orientation was similar to that of Hofstede's masculine nations. One implication for policymakers in feminine nations is that, although values such as welfare, service, and hospitality are important, being persistent, persuasive, and achievement-oriented is critical, especially during a pandemic's onset. It is likely that these values can facilitate social mitigation behaviors that, despite adverse psychological and economic effects (Brooks et al., 2020), are necessary to attenuate the growth rate of a pandemic. 


\section{Implications for Multinational Organizations}

While mitigation is critical from a healthcare perspective, so is reopening the nation from an economic standpoint. Questions such as how motivated people will be to return to normalcy when viral mutations (Starr et al., 2021) and a resurgence in lockdowns taking place in many nations (Rahim, 2021) require in-depth evaluation. MNEs will play a critical role in the post-COVID-19 world and, although many were not prepared, they realize that uncertainties caused by this pandemic will have a lasting impact on their functioning and survival (Van Assche \& Lundan, 2020). Successful transitioning will require training, workplace flexibility, informed leadership, and a supportive environment (Caligiuri, De Cieri, Minbaeva, Verbeke, \& Zimmermann, 2020). In addition, global value chains (GVCs) will have to be reconfigured (PerezBatres \& Treviño, 2020). Organizations will need to adapt to their consumers' evolving needs and behaviors, and, although innovative measures are essential, MNEs must understand that their implementation will require adaptation to the national cultural context. We address a few key issues that have attracted attention in managing the organizational crisis from COVID-19.

\section{Digitization}

Although the shift toward digitization was in progress well before the pandemic (Vendrell-Herrero, Bustinza, Parry, \& Georgantzis, 2017), social mitigation has led to an inevitable surge in virtualization and the use of electronic information (Almeida, Santos, \& Monteiro, 2020). Although MNEs are investing heavily in digital technologies to sustain operations (Papadopoulos, Baltas, \& Balta, 2020), the form and effectiveness of this shift will vary across nations based on their culture. Our argument follows Kedia and Bhagat (1988), who stressed culture's role in predicting the extent to which organizations in different nations accept, absorb, and diffuse technologies. For instance, cultural differences affect the design and structure of technology transferred across nations (Harvey, 1997), as well as the level of technological adoption (Li \& Kirkup, 2007). These findings challenge MNEs' capacity to take a universal approach to maintaining the current level of digitization mandated by pandemic restrictions in a post-pandemic world.

Specifically, differences will exist in the extent to which employees across different nations will tolerate large-scale and long-term digitization of professional activities. As an example, employees in collectivistic nations may find the virtual workplace devoid of context and meaning, which may not be the case with employees in individualistic nations. Thus, MNEs may have to implement different hiring, training, and support strategies to ensure adequate returns on their digital investments. This will include additional investments in cross-cultural training to ensure that employees develop a shared understanding of digital routines and collaborate effectively in virtual spaces. Further, cultural intricacies may be more salient in the virtual world, as employees may face ambiguity in recognizing and resolving culture-based differences that were more easily resolved through face-to-face communication ( $\mathrm{Li}, 2010)$. Although digitization is vital in the post-pandemic world, its implementation will require customization to cultural contexts. For example, while employees in high uncertainty avoidance nations may demand more formalization, those in more individualistic nations may require more customization and flexibility. Similarly, even though training and guidelines will be imperative, cross-national differences will exist in the extent to which formulating these tools requires employee participation. For example, in high power distance nations, MNEs may be better off setting clear standards and codes of conduct. However, in low power distance nations, engaging employees in planning will be essential to secure participation. It is yet to be learned whether spatial barriers that digitization attempts to break will lead to organizational efficiency or a psychologically distressed workforce.

\section{Global employees}

The rapid pace of globalization and foreign direct investment has increased the proportion of global employees in organizations (Caligiuri \& Bonache, 2016). While the goal of such hiring is to leverage opportunities from improved diversity and talent, its realization does not come without challenges (Stahl et al., 2012). Extant literature acknowledges issues that organizations face in managing global employees, including the difficulty of fostering inclusiveness, information sharing, and knowledge dissemination (Roberts, Kossek, \& Ozeki, 1998). In addition, global employees face challenges from acculturation, discrimination, and heightened job demands (Burke \& Ng, 2006). COVID-19 has added additional layers of complexity by limiting domestic and international travel, instigating stay-at- 
home orders, and eroding social interactions (Cho, 2020). While these factors confer public health benefits, they also create novel challenges. For instance, Cooke, Dickmann, and Parry (2020) noted that organizational changes implemented in response to COVID-19 would have a lasting impact on the work, behavior, and turnover of global employees. Similarly, Caligiuri et al. (2020) emphasized that the uncertainties and involuntary changes to work patterns caused by this pandemic have levied notable health, performance, and economic challenges for global employees.

Knowledge of the cultural context will be vital to resolving such challenges during the COVID-19 period and beyond. Our argument follows Palthe (2004), who found that host-country cultures play a vital role in influencing the psychological and social adjustment of global employees and their families. MNEs may lose their global competitiveness unless they invest in post-pandemic training to facilitate the cultural adjustment and adaptation of global employees and their families (e.g., Minbaeva, Rabbiosi, \& Stahl, 2018). They will also have to be mindful of tapping into their global employees' skills, as they are accustomed to working in integrated and relationship-oriented environments (Caligiuri \& De Cieri, 2021). In this case, employees from collectivistic and high uncertainty avoidance nations may be more likely to perceive the strain from increased social isolation than employees from individualistic and low uncertainty avoidance nations. Culture may also influence the extent to which national policies limit the inflow of global employees during and after COVID-19 (Brock, Shenkar, Shoham, \& Siscovick, 2008), which will affect the innovativeness, knowledge flow, and economic growth of MNEs in such nations (Cho, 2020).

\section{Global value chains}

COVID-19 has highlighted the crippling impact that a pandemic can levy on GVCs (Perez-Batres \& Treviño, 2020). Indeed, severe disruptions to the distribution of medical equipment, meat, paper products, personal protective equipment, and other consumer durables and non-durables illustrate the perils that MNEs face by relying on traditional GVCs and failing to mitigate disruptions. Some of the major challenges relate to issues surrounding how to increase the resilience of GVCs so as to make them more sustainable (Van Assche \& Lundan, 2020). Although a number of potential solutions, such as expanding international production sites, reshoring production, and diversifying supplier bases have been suggested (Gereffi, 2020), their use and success depends on the cultural context of the nations in which the MNE and its GVC partners are located.

For instance, it is likely that, because managers in individualistic and low uncertainty avoidance nations are more flexible and open to experimentation (Hofstede, 1994), they will perceive fewer vulnerabilities to restructuring their GVCs and engaging in new supply networks than managers from more collectivistic and high uncertainty avoidance nations. As such, MNEs in the former nations may be better positioned to reduce their dependency on one or a few suppliers and sustain their competitiveness and consumer responsiveness during and after the pandemic. However, it may be that managers in collectivistic and high uncertainty avoidance nations perceive lower trust in new and unproven business networks. Unfortunately, this tendency to shun innovative solutions to disruptions stemming from pandemics would place the organization at a greater risk of GVC systematic failure. Regarding the role of government, it has been argued that cooperation between MNEs and governments can be effective in mitigating GVC disruptions (Perez-Batres \& Treviño, 2020), as both have an inherent interest in maintaining supply chains during pandemics. Developing such partnerships would be more likely in high power distance nations, where citizens are more open to government mandates. Indeed, value from reshoring production and shifting/increasing supplier bases can only be achieved once cooperation develops between GVC business partners, which may require substantial investment in cultural sensitivity and training (Shapiro, Ozanne, \& Saatcioglu, 2008).

\section{Limitations and Future Research}

While making notable contributions, our research is not without limitations. First, because we focused on the initial three-month period in a nation after the first confirmed cases were reported, our findings may be less generalizable beyond the initial outbreak period. Future research should examine how the effect of government stringency, culture, and other contextual factors may evolve in predicting pandemic growth beyond this period and in repeated infection waves cross-nationally. Studies may also examine the extent to which these macro- 
level factors predict pandemic growth in subsequent infection waves. Second, although we performed exponential smoothing to resolve issues, such as discontinuities in daily case reporting, and examined alternate 7-day moving average and nonsmoothed case data, we acknowledge the limitations from differences in reporting practices across nations. As these practices become more consistent and reliable, research may dig deeper into analyzing the contextual embeddedness of pandemic growth. Finally, although our focus was to analyze culture's role in predicting pandemic growth that could offer meaningful implications for individuals, organizations, and society, not all factors may be examined in a single study. Hence, we acknowledge that other factors may be important (e.g., level of political polarization, trust in government), and future research may contribute by examining contextual interdependencies not captured herein.

\section{CONCLUSION}

By integrating insights from the cross-cultural, social psychology, and public health literatures, we have developed a nuanced model of pandemic response that enables governments to not only determine effective mitigation strategies based on contextual conditions but also to understand how to communicate their strategy to society, with the objective of saving lives while mitigating against a downturn in the economy. We hope that our findings will enable cross-national pandemic research to move toward a more contextualized and integrated explanation of pandemic response.

\section{ACKNOWLEDGEMENTS}

The authors would like to thank the Editor, Professor Dana Minbaeva and Journal of International Business Studies anonymous reviewers for their extremely constructive and detailed feedback that allowed us to improve our manuscript significantly.

\section{NOTES}

${ }^{1}$ The OWID database includes negative daily cases adjustment scores for a few countries in our sample (Ecuador, France, Italy, Jordan, Lithuania, Portugal, Spain). We examined daily case data in accordance with government sources used by the
ECDC (https://www.ecdc.europa.eu/en/ publications-data/sources-worldwide-data-covid-

19) to revise data. However, Ecuador and France were excluded from the study due to case data including several large negative case daily reports that could not be reconciled with government sources. In addition, we excluded Qatar which was an extreme outlier in terms of daily new cases per million (mean of 201.8 new cases per million, whereas the mean range was $0.02-70.5$ for other countries for the 91-day time period).

${ }^{2}$ The Oxford COVID-19 Government Response Tracker systemically collects and updates data on 24 indicators that are aggregated into a set of four indices (containment and health, stringency, economic support, and overall government response). The containment and health index extends the legacy stringency index with the addition of testing, contact tracing, facial coverings, and vaccination policies. The indices simply record the number and strictness of government responses and policies, and should not be interpreted as 'scoring' the appropriateness or effectiveness of a country's response (Hale et al., 2021). More details about the index can be obtained from: https://www.bsg. ox.ac.uk/research/research-projects/coronavirusgovernment-response-tracker

${ }^{3}$ A substantial proportion of countries $(n=107)$ had implemented health and containment measures prior to reporting COVID-19 cases. For the first day of reported cases, the lagged government stringency scores (14 days previous) was 0 for $37 \%$ of countries, $1-9.9$ for $37 \%$ of countries, and 10 or higher for $25 \%$ of countries. Two weeks later (i.e., on the first day of case reporting), the government stringency scores was 0 for only $9 \%$ of countries, $1-9.9$ for $18 \%$ of countries, $10-19.9$ for $45 \%$ of countries, and 20 or higher for $27 \%$ of countries.

${ }^{4}$ The six WGI dimensions are: voice and accountability, political stability and absence of violence, government effectiveness, regulatory quality, rule of law, and control of corruption. WGI scores are highly interrelated, so per Globerman and Shapiro (2003), we used the composite factor score (Eigenvalue $=5.221,87.02 \%$ variance explained) .

${ }^{5}$ The null model intraclass correlation coefficients showed that the proportion of total variance between countries was $34 \%$. We used full maximum likelihood estimation and compared variance explained (likelihood ratio tests using deviance statistics) between nested models. The likelihoodratio tests for the addition of level-1 variables were all significant at the $p<0.001$ level, in sequence: 
time $(\Delta$ deviance $=5012.02, d f=3)$; time sq. $(\Delta$ deviance $=4882.58, d f=4)$; government stringency $(\Delta$ deviance $=1549.28, d f=5)$; time $\times$ government stringency $(\Delta$ deviance $=6854.41, d f=$ $6)$.

${ }^{6}$ The likelihood-ratio tests for the addition of the cultural values cross-level interactions on to the baseline model with controls were significant (respectively, cultural values $\times$ time: $\Delta$ deviance $=$ $13.19, d f=4, p=0.011$; cultural values $\times$ time $\times$ government stringency; $\Delta$ deviance $=29.46, d f=4$, $p<0.001)$. The addition of cross-level moderating effects of cultural values on government stringency

\section{REFERENCES}

Allel, K., Tapia-Muñoz, T., \& Morris, W. 2020. Country-level factors associated with the early spread of COVID-19 cases at 5,10 and 15 days since the onset. Global Public Health, 15(11): 1589-1602.

Almeida, F., Santos, J. D., \& Monteiro, J. A. 2020. The challenges and opportunities in the digitalization of companies in a PostCOVID-19 World. IEEE Engineering Management Review, 48(3): 97-103.

Alves, J. C., Lovelace, K. J., Manz, C. C., Matsypura, D., Toyasaki, F., \& Ke, K. G. 2006. A cross-cultural perspective of selfleadership. Journal of Managerial Psychology, 21(4): 338-359.

Anderson, R. M., Heesterbeek, H., Klinkenberg, D., \& Hollingsworth, T. D. 2020. How will country-based mitigation measures influence the course of the COVID-19 epidemic? The Lancet, 395(10228): 931-934.

Ashraf, B. N. 2020. Economic impact of government interventions during the COVID-19 pandemic: International evidence from financial markets. Journal of Behavioral and Experimental Finance, 27: 100371. https://doi.org/10.1016/j.jbef.2020. 100371.

Berkman, E. T. 2018. The neuroscience of goals and behavior change. Consulting Psychology Journal: Practice and Research, 70(1): 28-44.

Beugelsdijk, S., Maseland, R., \& Hoorn, A. 2015. Are scores on Hofstede's dimensions of national culture stable over time? A Cohort Analysis. Global Strategy Journal, 5(3): 223-240.

Biddlestone, M., Green, R., \& Douglas, K. 2020. Cultural orientation, powerlessness, belief in conspiracy theories, and intentions to reduce the spread of COVID-19. British Journal of Social Psychology, 59(3): 663-673.

Bish, A., \& Michie, S. 2010. Demographic and attitudinal determinants of protective behaviours during a pandemic: $A$ review. British Journal of Health Psychology, 15(4): 797-824.

Borg, M. A. 2012. National cultural dimensions as drivers of inappropriate ambulatory care consumption of antibiotics in Europe and their relevance to awareness campaigns. Journal of Antimicrobial Chemotherapy, 67(3): 763-767.

Borg, M. A. 2014. Cultural determinants of infection control behaviour: understanding drivers and implementing effective change. Journal of Hospital Infection, 86(3): 161-168.

Brock, D. M., Shenkar, O., Shoham, A., \& Siscovick, I. C. 2008. National culture and expatriate deployment. Journal of International Business Studies, 39(8): 1293-1309.

Brooks, S. K., et al. 2020. The psychological impact of quarantine and how to reduce it: Rapid review of the evidence. The Lancet, 395(10227): 912-920. was not significant $(\Delta$ deviance $=2.58, d f=4, p=$ $0.63)$ with nonsignificant values $\times$ stringency interactions ranging from $p=0.239$ to $p=0.751$.

${ }^{7}$ Schwartz's (2006) societal cultural values scores consists of seven cultural value orientations grouped into three bipolar dimensions: autonomy/embeddedness, hierarchy/egalitarianism, and mastery/harmony. The autonomy score is the average of intellectual and affective autonomy. A positive value indicates a nation's inclination toward the former end of each dimension, while a negative value indicates inclination toward the latter end.

Burke, R. J., \& Ng, E. 2006. The changing nature of work and organizations: Implications for human resource management. Human Resource Management Review, 16(2): 86-94.

Caligiuri, P., \& Bonache, J. 2016. Evolving and enduring challenges in global mobility. Journal of World Business, 51(1): 127-141.

Caligiuri, P., \& De Cieri, H. 2021. Predictors of employees' preference for working from home post-pandemic. Business and Economic Research, 11(2): 1-9.

Caligiuri, P., De Cieri, H., Minbaeva, D., Verbeke, A., \& Zimmermann, A. 2020. International HRM insights for navigating the COVID-19 pandemic: Implications for future research and practice. Journal of International Business Studies, 51: 697-713.

Chen, S. X., et al. 2006. Reexamining Personal, Social, and Cultural Influences on Compliance Behavior in the United States, Poland, and Hong Kong. The Journal of Social Psychology, 146(2): 223-244.

Chen, X., \& Yu, B. 2020. First two months of the 2019 Coronavirus Disease (COVID-19) epidemic in China: Real-time surveillance and evaluation with a second derivative model. Global Health Research and Policy, 5(1): 1-9.

Chien, L.-C., \& Lin, R.-T. 2020. COVID-19 Outbreak, Mitigation, and Governance in High Prevalent Countries. Annals of Global Health, 86(1): 119. https://doi.org/10.5334/aogh.3011.

Cho, E. 2020. Examining boundaries to understand the impact of COVID-19 on vocational behaviors. Journal of Vocational Behavior, 119(1): 103437. https://doi.org/10.1016/j.jvb. 2020.103437.

Cho, H., \& Lee, J. S. 2015. The influence of self-efficacy, subjective norms, and risk perception on behavioral intentions related to the H1N1 flu pandemic: A comparison between Korea and the US. Asian Journal of Social Psychology, 18(4): 311-324.

Cooke, F. L., Dickmann, M., \& Parry, E. 2020. IJHRM after 30 years: Taking stock in times of COVID-19 and looking towards the future of HR research. The International Journal of Human Resource Management, 32(1): 1-23.

Corley, J. 2020. U.S. Government Response To COVID-19 Was Slow. But How Does It Compare To Other Countries? Forbes, https://www.forbes.com. Accessed 30 May 2020.

Daniels, M. A., \& Greguras, G. J. 2014. Exploring the nature of power distance: Implications for micro-and macro-level theories, processes, and outcomes. Journal of Management, 40(5): 1202-1229.

De Meulenaer, S., De Pelsmacker, P., \& Dens, N. 2018. Power distance, uncertainty avoidance, and the effects of source 
credibility on health risk message compliance. Health Communication, 33(3): 291-298.

Del Valle, S. Y., Mniszewski, S. M., \& Hyman, J. M. 2013. Modeling the impact of behavior changes on the spread of pandemic influenza. In P. Manfredi, \& A. D'Onofrio (Eds.), Modeling the interplay between human behavior and the spread of infectious diseases: 59-78. New York: Springer.

Deschepper, R., et al. 2008. Are cultural dimensions relevant for explaining cross-national differences in antibiotic use in Europe? BMC Health Services Research, 8(1): 1-9.

Fincher, C. L., Thornhill, R., Murray, D. R., \& Schaller, M. 2008. Pathogen prevalence predicts human cross-cultural variability in individualism/collectivism. Proceedings of the Royal Society B, 275(1640): 1279-1285.

Fischer, R., \& Mansell, A. 2009. Commitment across cultures: A meta-analytical approach. Journal of International Business Studies, 40(8): 1339-1358.

Fisher, M. \& Sang-Hun, C. 2020. How South Korea Flattened the Curve, The New York Times. https://www.nytimes.com/2020/ 03/23/world/asia/coronavirus-south-korea-flatten-curve.html. Accessed 20 May 2020.

Frey, C. B., Chen, C., \& Presidente, G. 2020. Democracy, culture, and contagion: Political regimes and countries responsiveness to COVID-19. Covid Economics, 18: 1-20.

Gelfand, M. J., et al. 2021. The relationship between cultural tightness-looseness and COVID-19 cases and deaths: A global analysis. The Lancet Planetary Health, 5(3): e135-e144.

Gereffi, G. 2020. What does the COVID-19 pandemic teach us about global value chains? The case of medical supplies. Journal of International Business Policy, 3(3): 287-301.

Globerman, S., \& Shapiro, D. 2003. Governance infrastructure and US foreign direct investment. Journal of International Business Studies, 34(1), 19-39.

Graafland, J., \& Noorderhaven, N. 2020. Culture and institutions: How economic freedom and long-term orientation interactively influence corporate social responsibility. Journal of International Business Studies, 51: 1034-1043.

Guy, J. \& Griffiths, J. 2020. Singapore threatens 6 months in jail for breaking social distancing laws. https://www.cnn.com/ 2020/03/27/asia/singapore-coronavirus-laws-scli-intl/index. html. Accessed 25 April, 2020.

Hale, T., et al. 2021. A global panel database of pandemic policies (Oxford COVID-19 Government Response Tracker). Nature Human Behaviour, 5: 529-538.

Harvey, F. 1997. National cultural differences in theory and practice. Information Technology \& People, 10: 132-147.

Heinrichs, N., et al. 2006. Cultural differences in perceived social norms and social anxiety. Behaviour Research and Therapy, 44(8): 1187-1197.

Hofstede, G. 1983. The cultural relativity of organizational practices and theories. Journal of International Business Studies, 14(2): 75-89.

Hofstede, G. 1994. Management scientists are human. Management Science, 40(1): 4-13.

Hofstede, G. 1998. Masculinity and femininity: The taboo dimension of national cultures. Thousand Oaks, CA: Sage.

Hofstede, G. H. 2001. Culture's consequences: Comparing values, behaviors, institutions and organizations across nations. Thousand Oaks, CA: Sage.

Hornsey, M. J., Harris, E. A., \& Fielding, K. S. 2018. The psychological roots of anti-vaccination attitudes: A 24-nation investigation. Health Psychology, 37(4): 307-315.

House, R. J., Hanges, P. J., Javidan, M., Dorfman, P. W., \& Gupta, V. 2004. Culture, leadership, and organizations: The GLOBE study of 62 societies. Thousand Oaks, CA: Sage.

Hsiang, S., et al. 2020. The effect of large-scale anti-contagion policies on the COVID-19 pandemic. Nature, 584(7820): 262-267.

Huynh, T. L. D. 2020. Does culture matter social distancing under the COVID-19 pandemic? Safety Science, 130(Oct): 104872. https://doi.org/10.1016/j.ssci.2020.104872.
Inglehart, R., \& Oyserman, D. 2004. Individualism, autonomy, and self-expression: The human development syndrome. In $\mathrm{H}$. Vinken, J. Soeters, \& P. Ester (Eds.), Comparing cultures: Dimensions of culture in a comparative perspective: 74-96. Leiden: Brill.

JHU (John Hopkins University). 2020. COVID-19 Dashboard by the Center for Systems Science and Engineering, Coronavirus Resource Center. John Hopkins University. Available at: https:// coronavirus.jhu.edu/map.html. Accessed 22 April, 2021.

Ji, Y., Zhou, E., Li, C., \& Yan, Y. 2015. Power distance orientation and employee help seeking: Trust in supervisor as a mediator. Social Behavior and Personality, 43(6): 1043-1054.

Jiang, S. 2020. Don't rush to deploy COVID-19 vaccines and drugs without sufficient safety guarantees. Nature, 579(19 March): 321.

Johnson, B. B., \& Slovic, P. 1995. Presenting uncertainty in health risk assessment: initial studies of its effects on risk perception and trust. Risk Analysis, 15(4): 485-494.

Johnson, J. P., \& Lenartowicz, T. 1998. Culture, freedom and economic growth: Do cultural values explain economic growth? Journal of World Business, 33(4): 332-356.

Kazak, A. E. 2020. Psychology is an essential science: American Psychologist highlights the role of psychology in understanding and addressing COVID-19. American Psychologist, 75(5): 605-606.

Kedia, B. L., \& Bhagat, R. S. 1988. Cultural constraints on transfer of technology across nations: Implications for research in international and comparative management. Academy of Management Review, 13(4): 559-571.

Kim, H. K., Ahn, J., Atkinson, L., \& Kahlor, L. A. 2020. Effects of COVID-19 misinformation on information seeking, avoidance, and processing: A multicountry comparative study. Science Communication, 42(5): 586-615.

Kirkman, B. L., Lowe, K. B., \& Gibson, C. B. 2006. A quarter century of culture's consequences: A review of empirical research incorporating Hofstede's cultural values framework. Journal of International Business Studies, 37(3): 285-320.

Kitayama, S., et al. 2018. Behavioral adjustment moderates the link between neuroticism and biological health risk: A USJapan comparison study. Personality and Social Psychology Bulletin, 44(6): 809-822.

Kwok, C. C., \& Tadesse, S. 2006. National culture and financial systems. Journal of International Business Studies, 37(2): 227-247.

Lavazza, A., \& Farina, M. 2020. The role of experts in the Covid19 pandemic and the limits of their epistemic authority in democracy. Frontiers in Public Health, 8: 356. https://doi.org/ 10.3389/fpubh.2020.00356

Lazarus, I. V., et al. 2020. COVID-SCORE: A global survey to assess public perceptions of government responses to COVID19 (COVID-SCORE-10). PLOS ONE, 15(10): e0240011.

Lee, J. A., Garbarino, E., \& Lerman, D. 2007. How cultural differences in uncertainty avoidance affect product perceptions. International Marketing Review, 24(3): 330-349.

Lee, S. T., \& Basnyat, I. 2013. From press release to news: mapping the framing of the $2009 \mathrm{H} 1 \mathrm{~N} 1 \mathrm{~A}$ influenza pandemic. Health Communication, 28(2): 119-132.

Li, N., \& Kirkup, G. 2007. Gender and cultural differences in Internet use: A study of China and the UK. Computers \& Education, 48(2): 301-317.

$\mathrm{Li}$, W. 2010. Virtual knowledge sharing in a cross-cultural context. Journal of Knowledge Management, 14(1): 38-50.

Markus, H., \& Kitayama, S. 1991. Culture and the self: Implications for cognition, emotion, and motivation. Psychological Review, 98(2): 224-253.

Minbaeva, D., Rabbiosi, L., \& Stahl, G. K. 2018. Not walking the talk? How host country cultural orientations may buffer the damage of corporate values' misalignment in multinational corporations. Journal of World Business, 53(6): 880-895.

Morita, H., Kato, H., and Hayashi, Y. 2020. International comparison of behavior changes with social distancing policies 
in response to COVID-19. https://doi.org/10.2139/ SSRN3594035

Ndubisi, N. O., Malhotra, N. K., Ulas, D., \& Ndubisi, G. C. 2012. Examining uncertainty avoidance, relationship quality, and customer loyalty in two cultures. Journal of International Consumer Marketing, 24(5): 320-337.

Newburry, W., \& Yakova, N. 2006. Standardization preferences: A function of national culture, work interdependence and local embeddedness. Journal of International Business Studies, 37(1): 44-60.

Nienaber, M. \& Chambers, M. 2020. Germans stage protests against lockdown measures, social distancing rules. Reuters. https://www.reuters.com/news/picture/germans-stageprotests-against-lockdown-idUSKBN22S0MS. Accessed May 30, 2020.

Nivette, A., et al. 2021. Non-compliance with COVID-19-related public health measures among young adults in Switzerland: Insights from a longitudinal cohort study. Social Science \& Medicine, 268: 113370. https://doi.org/10.1016/j.socscimed. 2020.113370.

Palthe, J. 2004. The relative importance of antecedents to crosscultural adjustment: Implications for managing a global workforce. International Journal of Intercultural Relations, 28(1): 37-59.

Papadopoulos, T., Baltas, K. N., \& Balta, M. E. 2020. The use of digital technologies by small and medium enterprises during COVID-19: Implications for theory and practice. International Journal of Information Management, 55: 102192.

Perez-Batres, L. A. \& Treviño, L. J. 2020. Global Supply Chains in Response to COVID-19: Adopting a Real Options Mindset. $A / B$ Insights, 20(3). Available at SSRN: https://ssrn.com/abstract= 3787132

Peterson, M. F., \& Smith, P. B. 2008. Social structures and processes in cross cultural management. In P. B. Smith, M. F. Peterson, \& D. C. Thomas (Eds.), Handbook of cross-cultural management research: 35-58. Thousand Oaks, CA: Sage.

Peterson, M. F., \& Wood, R. E. 2008. Cognitive structures and processes in cross cultural management. In P. B. Smith, M. F. Peterson, \& D. C. Thomas (Eds.), Handbook of cross-cultural management research: 15-33. Thousand Oaks, CA: Sage.

Pisano, G. P., Sadun, R., \& Zanini, M. 2020. Lessons from Italy's response to coronavirus. Harvard Business Review. https:// www.hbs.edu/faculty/Pages/item.aspx?num =57971

Rahim, Z. 2021. Europe starts 2021 by extending lockdowns as coronavirus cases spiral. London: CNN. https://www.cnn. com/2021/01/05/europe/european-coronavirus-lockdowns2021-intl/index.html Accessed 25 February 2021.

Raudenbush, S. W., \& Bryk, A. S. 2002. Hierarchical linear models: Applications and Data Analysis Methods (2nd ed.). Thousands Oaks, CA: Sage.

Roberts, K., Kossek, E. E., \& Ozeki, C. 1998. Managing the global workforce: Challenges and strategies. Academy of Management Perspectives, 12(4): 93-106.

Sagiv, L., Schwartz, S. H., \& Arieli, S. 2011. Personal values, national culture and organizations: Insights applying the Schwartz value framework. In N. N. Ashkanasy, C. Wilderom, \& M. F. Peterson (Eds.), The handbook of organizational culture and climate: 515-537, (2nd ed.). Newbury Park, CA: Sage.

Scarabel, F., Pellis, L., Bragazzi, N. L., \& Wu, J. 2020. Canada needs to rapidly escalate public health interventions for its COVID-19 mitigation strategies. Infectious Disease Modelling, 5: $316-322$.

Schwartz, S. H. 2006. A theory of cultural value orientations: Explication and applications. Comparative Sociology, 5(2): 137-182.

Shane, S. 1995. Uncertainty avoidance and the preference for innovation championing roles. Journal of International Business Studies, 26(1): 47-68.

Shapiro, J. M., Ozanne, J. L., \& Saatcioglu, B. 2008. An interpretive examination of the development of cultural sensitivity in international business. Journal of International Business Studies, 39(1): 71-87.

Simon, H. A. 1979. Information processing models of cognition. Annual Review of Psychology, 30(1): 363-396.

Singer, J. D., \& Willett, J. B. 2003. Applied longitudinal data analysis: Modeling change and event occurrence. New York: Oxford University Press.

Smith, P. B. 2015. To lend helping hands: In-group favoritism, uncertainty avoidance, and the national frequency of prosocial behaviors. Journal of Cross-Cultural Psychology, 46(6): 759-771.

Smith, P. B., Peterson, M. F., \& Schwartz, S. H. 2002. Cultural values, sources of guidance, and their relevance to managerial behavior: A 47-nation study. Journal of Cross-Cultural Psychology, 33(2): 188-208.

Smith, R. D. 2006. Responding to global infectious disease outbreaks: lessons from SARS on the role of risk perception, communication and management. Social Science \& Medicine, 63(12): 3113-3123.

Stahl, G., et al. 2012. Six principles of effective global talent management. Sloan Management Review, 53(2): 25-42.

Starr, T. N., et al. 2021. Prospective mapping of viral mutations that escape antibodies used to treat COVID-19. Science, 371(6531): 850-854.

Su, Y., et al. 2020. Examining the impact of COVID-19 lockdown in Wuhan and Lombardy: a psycholinguistic analysis on Weibo and Twitter. International Journal of Environmental Research and Public Health, 17(12): 4552. https://doi.org/10.3390/ ijerph17124552.

Sully De Luque, M. F., \& Sommer, S. M. 2000. The impact of culture on feedback-seeking behavior: An integrated model and propositions. Academy of Management Review, 25(4): 829-849.

Taylor, M. 2000. Cultural variance as a challenge to global public relations: A case study of the Coca-Cola scare in Europe. Public Relations Review, 26(3): 277-293.

Tufekci, Z. 2020. Why telling people they don't need masks backfired. The New York Times. https://www.nytimes.com/ 2020/03/17/opinion/coronavirus-face-masks.html. Accessed 25 April 2020.

Tyler, T. R., Lind, E. A., \& Huo, Y. J. 2000. Cultural values and authority relations: The psychology of conflict resolution across cultures. Psychology, Public Policy, and Law, 6(4): 1138-1163.

United Nations Population Division. 2019. World Population Prospects: The 2019 Revision. New York: United Nations. https://population.un.org/wpp/.

$U z$, I. 2015. The index of cultural tightness and looseness among 68 countries. Journal of Cross-Cultural Psychology, 46(3): 319-335.

Van Assche, A., \& Lundan, S. 2020. From the editor: COVID-19 and international business policy. Journal of International Business Policy, 3: 273-279.

Van Bavel, J. J., et al. 2020. Using social and behavioural science to support COVID-19 pandemic response. Nature Human Behaviour, 4: 460-471.

Vendrell-Herrero, F., Bustinza, O. F., Parry, G., \& Georgantzis, N. 2017. Servitization, digitization and supply chain interdependency. Industrial Marketing Management, 60: 69-81.

Wagner, J. A., III. 1995. Studies of individualism-collectivism: Effects on cooperation in groups. Academy of Management Journal, 38(1): 152-173.

Wenzel, A. 2019. To verify or to disengage: Coping with "fake news" and ambiguity. International Journal of Communication, 13: 1977-1995.

Westjohn, S. A., Magnusson, P., Peng, Y., \& Jung, H. 2019. Acting on anger: Cultural value moderators of the effects of consumer animosity. Journal of International Business Studies. https://doi.org/10.1057/s41267-019-00289-7.

WHO (World Health Organization). 2020. Rational use of personal protective equipment (PPE) for coronavirus disease 
(COVID-19): Interim guidance. https://apps.who.int/iris/ handle/10665/331498 Accessed 20 April 2020

Wolf, L. J., Haddock, G., Manstead, A. S., \& Maio, G. R. 2020. The importance of (shared) human values for containing the COVID-19 pandemic. British Journal of Social Psychology, 59(3): 618-627.

World Bank. 2020a. World development indicators. Available at: https://databank.worldbank.org/source/world-developmentindicators

World Bank. 2020b. Worldwide governance indicators. Available at: Documents https://info.worldbank.org/governance/wgi/Home/

Zhou, X., Zafarani, R., Shu, K., \& Liu, H. 2019. Fake News: Fundamental theories, detection strategies and challenges. In WSDM 2019-Proceedings of the 12th ACM International Conference on Web Search and Data Mining: 836-837. https://doi.org/10.1145/3289600.3291382.

\section{ABOUT THE AUTHORS}

Ratan J. S. Dheer is an Associate Professor of Management at the College of Business, Eastern Michigan University, USA. His research interests include cross-cultural issues, multiculturalism, entrepreneurship, immigrant and minority entrepreneurship, entrepreneurial cognitions, and institutional theory. He has published in the Journal of International Business Studies, Journal of World Business, Entrepreneurship Theory and Practice, Small Business Economics, Human
Resource Management Review, and the Journal of Vocational Behavior, among others. He earned his PhD from Florida Atlantic University.

Carolyn P. Egri is the Associate Dean, Research and International, and William J.A. Rowe EMBA Alumni Professor in the Beedie School of Business at Simon Fraser University, Canada. Her research interests focus on cultural values, international management, environmental sustainability, and corporate social responsibility.

Len J. Treviño is the SBA Communications Distinguished Professor in International Business and Director of IB Programs in the College of Business at Florida Atlantic University. His research focuses on the multinational enterprise, foreign direct investment, institutional theory, internationalization, and COVID-19. His work includes numerous articles in Journal of International Business Studies, Journal of International Business Policy, Journal of Management, and Journal of World Business, among many others. His earned his $\mathrm{PhD}$ in international business and strategic management from Indiana University.

Publisher's Note Springer Nature remains neutral with regard to jurisdictional claims in published maps and institutional affiliations.

Accepted by Dana Minbaeva, Area Editor, 26 May 2021. This article has been with the authors for two revisions. 